\title{
A Amazônia Central e seus peixes (*)
}

Wiliiam I. Fink (')
Sara V. Fink (')

\begin{abstract}
Resumo
O sistema do rio Amazonas é caracterizado pela sua grande extensão (ele drena uma área de cerca de 6,5 milhōes de quilômetros quadrados), sua grande profundidade (de $90 \mathrm{~m}$ ou mais em alguns lugares), a topografia plana de sua bacia de drenagem, os ciclos anuais de períodos de cheia e seca, e a estrutura geológica da área de drenagem. O ecossistema da Amazônia Central é complexo e os tipos de "habitat" dentro dele são numerosos, com ampla sobreposição e intergradação de categorias. Um fator especialmente importante no "habitat" aquático é o tipo de água ("branca", "preta" ou "clara"), uma característica que está relacionada ao caráter geológico e a flora da área de drenagem. Mudanças cíclicas no nível da água e flutuações associadas à disponibilidade de oxigênı são dois fatores que exercem considerável influência sobre a biologia dos peixes da Amazônia Central. Os locais de coleta do "Alpha Helix" Fase IV são sucintamente descritos. A sistemática e evolução da maioria dos grupos de peixes do Amazonas são muito pouco conheciáas; a incapacidade para identificar todos os peixes examinados e a falta de hipóteses evolucionárias de parentesco bem demonstradas para basear as comparaçōes apresentam problemas para o biólogo comparativo. Um breve estudo dos aspectos gerais da filogenia e da história natural dos peixes examinados pela Fase IV é apresentado, incluincio, quando possível, informação sobre preferência de habitat, alimento, e outros aspectos da biologia dos peixes.
\end{abstract}

Como uma introdução para os trabalhos seguintes de bioquímica e fisiologia comparada das hemoglobinas de alguns peixes da Amazônia, tentamos abaixo esboçar alguns fatos básicos sobre o sistema do rio Amazonas e o ecossistema das terras baixas da Amazônia e sobre a biologia e o parentesco evolucionário dos peixes da Amazônia. O objetivo é colocar os aspectos bioquímicos e fisiológicos desses peixes no contexto dos organismos dos quais eles são uma parte e o ecosistema ao qual apresentam uma resposta adaptativa. Referência especial será feita ao meio ambiente e aos peixes encontrados pela expedição do "Alpha Helix" Fase IV à Amazônia Central (ver Fig. 1).

\section{CARACTERÍSTICAS FÍSICAS DO SISTEMA DO RIO}

Embora a magnitude não seja a única razão para o impressionante e único caráter do sistema desse rio, certamente é o traço mais peculiar. O rio Amazonas é, sem dúvida, a maior drenagem de água doce do mundo. O fluxo do Amazonas constitui 15 a 20 por cento da água doce lançada nos oceanos num ano; em média, 218 metros cúbicos de água verte no Atlântico a cada segundo (Sioli, 1967). "Cơm um fluxo de cinco vezes o do Congo e 12 vezes o do Mississippi, o Amazonas... lança tanta água no Atlântico a cada 24 horas quanto passa pelo Tâmisa, de Londres, num ano" (Meggers, 1971). O Amazonas é navegável por navios marítimos rio acima até lquitos, Peru, mais de três-quartos da transversal do continente. Essas ilustrações talvez sejam mais compreensíveis quando se considera que o Amazonas e seus afluentes drenam uma porção muito grande do continente sul-americano aproximadamente 6,5 milhões de quilômetros quadrados (incluindo a drenagem do Tocantins) - e além da maioria dessa área de dre nagem, a chuva anual é alta, atingindo de 1.500 a $3.000 \mathrm{~mm}$ anualmente (Haffer, 1974).

A profundidade do Amazonas, por si e de vários dos maiores afluentes, pelo menos em seus limites mais baixos, constitui outra característica incomum do sistema do rio amazônico. A profundidade do curso mais baixo do Amazonas (leste da confluência como o rio Negro) está por volta de 25 a 30 metros e aumenta de duas a três vezes em alguns lugares (Lowe-McConnell, 1975; Sioli, 1967; Meggers, 1971); uma equipe da U.S. "Geological Sur-

(•) - Versão original inglesa publicada em Comp. Blochem. Physiol. vol. 62A (1). 1979

(1) - Museum of Comparative Zoology, Harvard, Universi ty, Cambridge, Massachusetts, 02138. 


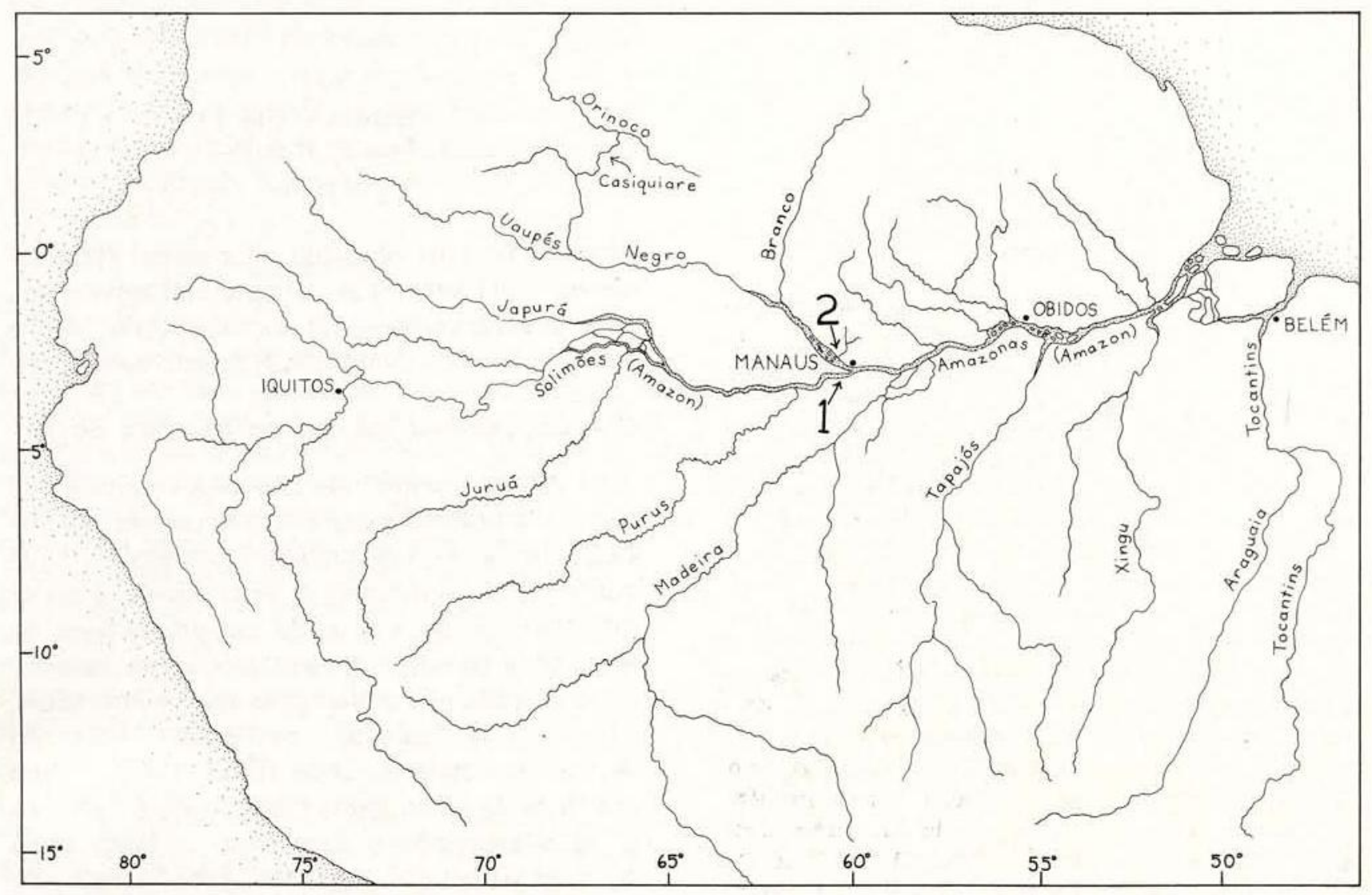

Fig. 1 - O maior afluente do rio Amazonas. Os locais de coleta do Alpha Helix Fase IV foram: 1 área do lago de Janæuacá, 2. área do rio Cuieiras.

vey" encontrou 10 lugares no baixo Amazonas com uma profundidade de $90 \mathrm{~m}$ ou mais (Sioli, 1967). Grande parte dos maiores afluentes do Amazonas forma "bocas de lago" muito profundas pelas quais os mesmos entram no Amazonas; a profundidade da do rio Negro tem sido registrada como tendo $93 \mathrm{~m}$, muito abaixo, portanto, do nível do mar. Essas "bocas de lago" parecem ser mais vales de erosão fluvial, talhados como um resultado da queda do nível do mar durante a última glaciação e inundação subseqüente pelo aumento do nível do mar (Marlier, 1973). Na Amazônia Central, essa profundidade incomum demonstra que os maiores leitos de rios tenham tamanhos consideráveis mesmo durante os períodos de níveis de água mais baixos.

Um terceiro fatơr de maior importância que contribui para a característica única deste sistema do rio é a topografia notavelmente plana da maior parte da área da bacia. Exce- tuando somente os Andes na borda oeste do continente, não há montanhas maiores ocorrendo na drenagem amazônica. Um leito de lago Terciário de água doce cobre uma grande área, em forma de cunha, imediatamente a leste dos Andes e se estende numa faixa ao longo do curso do baixo Amazonas; a maior parte do restante da drenagem é formada de rochas ígneas e metamórficas do Pré-cambriano e Paleozóico dos escudos Brasileiro e Guianense e é levemente ondulado, salientando, a intervalos, por baixos cumes representando as raizes de antigas montanhas. Como resultado dessa topografia, há raras cachoeiras extensas na bacia, no exterior dos Andes e o Amazonas por si cai somente $65 \mathrm{~m}$ entre a fronteira leste do Peru e o oceano Atlântico, numa distância de aproximadamente $3.000 \mathrm{~km}$ (Meggers, 1971).

Um outro fator relevante formando a peculiaridade desse sistema de rio é o ciclo anual 
de períodos de cheia e seca. A precipitação na drenagem do Amazonas é sazonal em intensidade, criando flutuações no nível da água de $6 \mathrm{~m}$ (em Iquitos, Peru), a $17 \mathrm{~m}$ (nos limites superiores do afluente noroeste, Japurá), a $4 \mathrm{~m}$ na fronteira da foz do Amazonas. Na Amazônia Central, uma crista de 10 a 15 m, ocasionalmente mais, ocorre nos leitos do rio principal por volta de junho (Marlier, 1973; LoweMcConnel, 1975) .

Um fator final caracterizador do sistema do rio Amazonas e da Amazônia como um todo, consiste nos atributos geoquímicos da área de drenagem. Nem as rochas Pré-cambrianas e Paleozóicas dos escudos Brasileiro e Güianense, nem os extremos depósitos do leito do lago Terciário fornecem quantidades apreciáveis e minerais e sais necessários para a subsistência da vida. Com exceção dos afloramentos restritos de rochas carboníferas do norte e sul do vale do baixo Amazonas, localizado em sua união, somente a jovem rocha dos Andes produz tais nutrientes em quantidades insignificantes. Como resultado, uma forma distinta existe entre a química do solo e da água da planície inundada do Amazonas, onde as águas são comparativamente ricas e o solo recebe renovação anual nas inundações sazonais, e a maior parte remanescente da Amazônia, onde as águas e solos têm muito poucos minerais e quase falta de sais (Sioli, 1968).

\section{"Habitats" aquáticos da amazônia central}

As características físicas esboçadas acima estabelecem o estágio para um ecossistema aparentemente complexo e ainda pouco conhecido. Alguns aspectos desse ecossistema, particularmente aqueles que afetam a fauna de peixes são discutidos abaixo numa forma breve. Um esforço foi feito para caracterizar tipos discretos de habitat, mas uma grande quantidade de sobreposições e intergradaçōes entre esses tipos pode ocorrer, dadas em parte, às flutuações no nível de água e resultantes mudanças e intercombinação de tipos de habitats.

Certamente as formaçöes aquáticas na Amažônia Central provocam descrições fáceis na linguagem da limnologia de zona temperada. Os três fatores da flutuação sazonal do nível da água, um sistema ribeirinho perenalmente extenso e um relevo topográfico baixo, combinam-se para produzir uma "paisagem" aquática complexa e extensa nas quais condições ribeirinhas e lacustres desaparecem. Formações na planície inundada do rio principal (a várzea) incluem não somente o leito do rio principal, mas uma rede de lagos, braços e córregos e canais intercomunicantes (uma pequena amostra pode ser vista na Fig. 2a). A floresta inundada (igapó) e pastos alagados (campos) também ocorrem, algumas vezes, desaparecendo, em formações de águas abertas (Fig. 2b). A área além, na qual tais informações de várzea ocorrem, é extensa, uma vez que a várzea atinge uma média de $48 \mathrm{~km}$ de largura (LoweMcConnell, 1975) e é muito mais larga, até $100 \mathrm{~km}$, em algumas áreas (Junk, 1970). A quantidade de habitats como lagos na várzea é muito maior durante a cheia da água do que nos períodos de seca, uma vez que várias formações periféricas ao leito do rio principal aumentam seu volume por muitos metros cúbicos e em muitos casos permanecem largamente inundados por um período de vários meses (Marlier, 1967).

Formações aquáticas do lado de fora da várzea são também de considerável variedade e passam por tipos similares de transformações durante os períodos de cheia. Essas formações incluem córregos (igarapés) e rios que fluem sobre terras mais altas para fora da planície inundada do Amazonas (terra firme); formações como lago nos cursos médios e inferiores de tais rios e córregos; e floresta alta inundada ou pantanosa, floresta baixa e pastos. Como na várzea, as características lacustres das partes largas das formaçōes como lago dos rios e córregos aumentam durante os períodos da cheia, quando a zona de inundação (igapó) ao longo dos curso d'água é inundada e à jusante das águas altas diminuem o fluxo de afluentes (Marlier, 1967). A floresta inundada ou pantanosa, arbusto, e pasto podem ocorrer ou formam o igapó ao longo dos cursos d'água.

Dentro de muitas dessas formações aquáticas, águas de características variadas podem ocorrer. Na Amazônia Central, as águas podem ser classificadas em três tipos gerais, embora deva ser enfatizado que pode haver intermediá- 
rios. Esses três tipos são "branca", "preta" e "clara". As diferenças na qualidade da água parecem estar associadas às diferenças nas características geológicas e no caso das águas "clara" e "preta", ao tipo de solo e vegetação presente na área de represa de cada curso d'água (Sioli, 1964). Os rios de água "branca" fluem dos Andes e sua cor turva pálida supōese ser causada pela grande carga de aluvião suspensa; o Amazonas, por sì só, permanece essencialmente como um rio de água branca em todo o seu curso até sua foz, não obstante a contribuição maior que ele recebe dos rios de outros típos de água. Deduzindo suas características químicas da jovem rocha andina, sua água é comparativamente rica em minerais e sais e tem um valor de $\mathrm{pH}$ mais alto, por volta do neutro - do que a maioria de outras águas amazonianas. A água "branca" constitui um importante, mas não o único, ingrediente na maioria das formações de várzea periféricas ao leito do rio principal; pequenos córregos compostos somente de águas correntes mais claras também podem ocorrer. Dependendo do período do ano, lagos, braços e canais recebem água "branca", água da chuva e água de enxurrada, em proporções variadas (Schmidt, 1973; Marlier, 1967).

Além da maior parte da Amazônia, os 2 tipos de água remanescentes, "preta" e "clara", derivam seu conteúdo mineralógico da rocha antiga dos escudos Brasileiro e Güianense ou dos sedimentos fluviais e de lagos Terciários erodidos desses depósitos de escudos antigos. Como resultado, eles são muito pobres em minerais e sais e mais ácidos que a água "branca" (Klinge \& Ohle, 1964; Sioli, 1968) com valores de $\mathrm{pH}$ variando de cerca de 4 ou 5 em pequenos córregos a somente levemente ácido nos cursos inferiores dos rios maiores (Sioli, 1967). As diferenças entre os dois tipos de água parecem estar associadas a diferenças na ação do nível da água, tipo de solo e tipo de vegetação. Contudo, deve-se estabelecer que embora tipos de água "clara" e "preta" sejam distintos, cada um, em suas formas mais pronunciadas, parecem graduar, cada uma, en suas formas menos pronunciadas. Nos córregos da floresta pluvial, por exemplo, foram encontradas águas que variam na cor entre o amarelado, oliva e marrom ou marrom- avermelhado (Sioli, 1964; Fittkau, 1967), e a tipificação das águas de algumas formações de várzea é igualmente problemática. Em termos gerais, contudo, as diferenças entre esses dois tipos de água podem ser caracterizados como se segue.

Aguas "claras", de acordo com Sioli (1964), surgem em localidades onde o solo é argiloso, a vegetação consiste de uma típica floresta alta pluvial (mata), e a terra não está sujeita à inundação extensa ou lixiviação. Os solos argilosos dos quais as águas "claras" fluem, embora pobres, tendem a ter conteúdo mineral levemente mais alto e conteúdo húmico inferior do que os solos dos quais as águas "pretas" fluem (Stark, 1970) tornando as águas "claras" com conteúdo mineral levemente maior e menos ácido que a água "preta" (Klinge \& Ohle, 1964; Sioli, 1957). A predominância de igarapés de água "clara" nas áreas represadas dos afluentes do baixo Amazonas: - rio Xingu e rio Tapajós - faz desses os maiores rios de água clara na Amazônia.

Aguas "pretas", em sua forma pronunciada, parecem pretas insitu e amareladas ou cor de chá num copo. De acordo com hipóteses atuais, essas águas se originam em terra plana que é altamente lixiviada e freqüentemente pouco drenada, permanecendo alagada por muitos meses, cada ano (Marlier, 1973). Na Amazônia Central, essas águas parecem estar associadas a um tipo de solo arenoso, lixiviado e poroso (podzol), um solo que tende mesmo a ter menos conteúdo mineral do que os solos argilosos tropicais, e com uma certa vegetação consistindo ou de um tipo de floresta de baixa pluviosidade (caatinga do rio Negro) ou vegetação aparente misturada de árvore e arbusto (campinas) (Sioli, 1967). A causa da coloração escura da água é presença de "ácidos húmicos", e talvez outros componentes vegetais secundários, lixiviados da camada superficial da palha caída e húmus do solo dos podzóis tropicais (Klinge \& Ohle, 1964; Janzen, 1974). A área mais extensa de podzóis com caatinga ou campinas na Amazônia ocorre na área superior da drenagem do rio Negro, e o rio Negro é o maior rio de água "preta" da Amazônia; contudo, condições similares tiveram uma distribuição espalhada através da Amazônia Central e muitos igarapés 
e rios de terra firme que consistem desse tipo de água.

As características desses tipos de água têm importantes conseqüências para a qualidade de vários tipos de "habitats" na Amazônia Central e para os modos de vida dos peixes que vivem dentro deles. A maior riqueza das águas "brancas" promove um desenvolvimento substancialmente maior da planta aquática, incluindo fitoplancton, capins alagados (campos), e "campinas flutuantes", pequenas ilhas de plantas aquáticas flutuantes habitadas por uma fauna diversa (Marlier, 1967; Junk, 1970). Particularmente em muitas formações de várzea periféricas ao leito do rio principal enriquecidas pelas águas "brancas" mas com uma turbidez baixa, o desenvolvimento do fitoplancton é relativamente vasto (Fisher, neste volume). Essa vida vegetal, por sua vez, mantém uma rica e diversa comunidade animal. Como pode ser esperado, o "habitat" da linha da margem parece manter mais biomassa e maior número de espécies em invertebrados bem como em peixes,, do que as águas abertas dos lagos e canais (experiência do autor senior; Marlier, 1967); como a ictiofauna desses dois habitats em comparação com a fauna das águas abertas do leito do rio principal é incerta.

Habitats de água "preta" e "clara" da terra firme parecem razoavelmente óbvias para manter menos crescimento de plantas aquáticas do que águas "brancas" com algas abuntes de variedade verde azulada e somente crescimento limitado de uns poucos tipos de plantas aquáticas superiores (Fittkau, 1967; Marlier, 1967). Uma pequena quantidade de isolação na maioria dos igarapés de floresta pluvial deve ser um fator desses baixos niveis de produção primária. Nas águas relativamente "claras" da mata da floresta pluvial, contudo, esses baixos níveis não sảo aparentemente restringentes a uma ictiofauna grande e diversa, onde Fittkau (1967) encontrou um número entre 30 e 50 espécies. Uma indicação da importância dos recursos alimentícios terrestres para peixes de habitats de floresta pluvial pode ser vista no estudo de Saul (1975) no Equador," onde ele encontrou insetos terrestres, particularmente formigas, compondo uma grande proporção da dieta de muitos peixes. Em grandes rios de água "clara", o crescimento de algas e "campinas flutuantes" aparentemente ocorrem (Sioli, 1964), embora sua amplitude seja incerta.

A quantidade e diversidade de peixes, bem como de outros organismos para serem encontrados em habitats de água "preta" é uma questão incerta. Há crenças de que rios de água "preta" são pobres em número de espécies e número absoluto de organismos, a uma hipótese sobre a toxidade" de águas "pretas" deve-se aos defensivos químicos da planta que têm sido liberados (Janzen, 1974); mas a extensão na qual a fauna de habitats de água "preta" realmente difere de outros habitats similares de terra firme, não foi investigada. As "bocas de lago" do rio Negro aparentemente não mantêm produção primária para a extensão encontrada no Tapajós (Sioli, 1964), mas se isso é devido aos componentes presentes na água ou aos niveis baixos da penetração de luz, não está claro. Muitas espécies parecem estar restritas às águas "pretas" da drenagem rio Negro - rio Orinoco (Venezuela), mas algumas espécies ocorrem em ambas as águas: "branca" e "preta".

Em suma, várias combinações da formação aquática, qualidade da água e produção primária associada a cadeias alimentares podem ocorrer. Embora ambos os graus de separação de faunas dos peixes entre os habitats resultantes e a quantidade de diferenciação dos modos de vida dentro desses habitats sejam incertos, devemos estar cientes das abundantes possibilidades que parecem importantes para a exploração da biologia dos peixes amazônicos. Por esta razão, um esboço dos tipos gerais de habitats possíveis para cada um dos três tipos de água, é dado abaixo; dentro de cada um desses tipos gerais, algumas separações de nicho baseadas no córrego e substrato podem ocorrer, particularmente como indicado. Certamente para quase todas as categorias, algumas separações de nichos com base na profundidade da coluna de água (camada bêntica, camada mediana e camadas superficiais) ocorrem. Os nichos dentro do habitat de igarapé são baseados em Fittkau (1967).

1. águas abertas de rios

2. águas abertas de lagos, braços e canais 
3. áreas de ambos margem acima

a - graminosa (campo) - talvez incluindo o habitat de "campina flutuante".

b - arborizado

c - praia lamacenta

$\mathrm{d}$ - praia arenosa

4. áreas alagadas

a - graminosa (campos, campinas)

b - arborizada (igapó, caatinga)

5. Córregos (igarapés)

a - águas correntes sobre substrato duro (areia, raízes ou madeira caida, rocha)

b - águas lentas e reservatórios calmos sobre substrato lamacento e coberto de detritos (folhas e galhos de árvores).

Dois parâmetros ambientais que exercem considerável influência sobre a biologia de peixes da Amazônia Central são as mudanças cíclicas no nível da água e flutuações associadas na disponibilidade de oxigênio. Por causa dessa influência considerável e em face de a sua influência ser sentida através de todos os habitats, essas duas variáveis merecem atenção especial.

Como são pouco conhecidas as histórias da vida da maioria dos peixes amazônicos, os modos preciosos nos quais o ciclo das estações úmida e seca afeta os peixes, podem somente ser conjecturados. Contudo, as vastas alterações na extensão e qualidade do habitat têm algumas consequeências gerais que podem ser delineadas. Quando as águas estão altas, os peixes estão dispersos nos afluentes dos rios principais ou sobre o assoalho das savanas e o alimento é abundante. Durante a estação seca, como o nível da água cai, muitos peixes são forçados por corrente abaixo ou a reservatórios e podem acomodar-se num espaço vital restrito, de modo gradativo. As fontes de alimento para a maioria dos peixes (exceto peixes predadores) tornam-se extremamente escassos, de forma que muitas espécies cessam completamente a sua alimentação e as reservas de gordura armazenadas são utilizăasas.

Tensões de oxigênio, embora consistentemente mais baixas do que são usuais nas águas doces de climas mais frios, são especialmente baixas sob as condições de estagnação que ocorrem durante os picos de ambos os períodos: de cheia e seca. Em média, para formações lacustres, termoclinas estáveis podem desenvolver-se durante períodos de cheia e resultam em condições hipóxicas a anóxicas nos leitos inferiores das águas. Tal hipóxia, aparentemente se estendendo sobre vários meses, tem sido observada em formaçöes lacustres da várzea mas pode ser menos pronunciada em lagos de terra firme (Schmidt, 1973; Marlier, 1967). Viveiros de peixes e pequenos lagos são mais apropriados para experimentarem modificações periódicas devidas à mistura introduzida pelo vento, mas quando a mistura cessa ou é evitada pela floresta circundante, a hipóxia pode de novo resultar, particularmente em leitos de águas mais baixas. Estagnação e hipóxia também ocorrem em águas de florestas inundadas, devidas primariamente a falta de movimentação, mistura pelo vento e fotossíntese sob cobertura sombreada (Carter, 1934; Kramer et al., no prelo). Durante a estação seca, pequenas lagoas deixadas por águas vazantes podem desenvolver hipóxia extrema quando a demanda de oxigênio biológico por metro cúbico é tão alta que mesmo as camadas da superfície da água se tornam esgotadas.

Os vários peixes da Amazônia que têm evoluído para lidar com a escassez de oxigênio e com o desaparecimento de vastas áreas de habitat durante os períodos de água baixa, são alguns dos temas principais de sua história evolucionária. Como deve ser esperado, aqueles peixes que habitam os habitats bênticos ou de águas rasas das linhas da margem apresentam, a maioria, notáveis adaptações. Essas adaptações incluem a habilidade de respirar ar atmosférico (em Arapaima, Hoplerythrinus, Hoplosternum, Electrophorus, Synbranchus); o deslizar sobre o leito da superfície oxigenada (Osteoglossum, alguns ciprinodontes); o estivar (a pirambóia, Lepidosiren) ou permanência na lama por longos períodos (Synbranchus); e produção de ovos que podem resistir à dissecação e incubar quando o nível da água sobe novamente (alguns ciprinodontes). Alguns peixes tais como Hoplosternum e Synbranchus, podem deslocar-se com facilidade nas superfí- 
cies secas ou quase secas e assim são capazes de deslocar-se de uma lagoa seca a áreas mais úmidas. Além disso, alguns peixes são capazes de utilizar metabolismo anaeróbico por um grande período (Hochochka \& Somero, 1971; Hochochka, comunicação pessoal). Ademais, a maioria dos peixes amazônicos podem sobreviver em águas com conteúdo de oxigênio muito baixo e mais ácido do que muitos peixes de zona temperada poderiam suportar.

Os peixes de respiração aérea foram de particular interesse aos membros da Fase IV. A questão óbvia a considerar é se esses peixes têm hemoglobinas especializadas para comportar-se com esse modo de vida. A fauna amazônica apresenta um modelo experimental particularmente bom nesse sentido por causa da presença de respiração aérea em gêneros de linhagens filogeneticamente distantes. Esses gêneros com linhagem filogeneticamente distantes podem ser comparados com cada um dos outros e também com seus parentes sem respiração aérea. O par mais proximamente congênere de respiração aérea e não aérea é Hoplias malabaricus (com respiração não aérea) e Hoplerythrinus unitaeniatus (com respiração aérea). Outros pares embora menos congêneres são Osteoglossum bicirrhosum (respiração não aérea) e Arapaima gigas (respiração aérea); e alguns dos bagres loricarídeos.

\section{LOCAIS DE COLETA DA FASE IV}

Os lugares de coleta da Fase IV foram aérea de confluência do rio Solimões (chamado em muitos mapas não brasileiros simplesmente de rio Amazonas) e o rio Negro (Fig. 1). A maioria das coletas foi feita no rio Solimões numa área a cerca de $50 \mathrm{~km}$ acima da confluência com o rio Negro. Naquela área e durante aquela estação (novembro e dezembro) o nível do rio atingia seus pontos mais baixos e começava a subir novamente. O barco ficou ancorado margem sul do rio, próximo a um canal comunicando com um grande lago, o lago Janauacá. O canal, por si só, (Fig. 2b,c) nesse tempo media $20 \mathrm{~m}$ de largura e estava fluindo do lago para o rio; durante a subida dos níveis d'ágúa do rio, o fluxo foi revertido e a largura do canal permaneceu estável. A maioria das coletas foi feita nesse canal (chamado paraná de Janauacá por Schmidt (1973), mas algumas outras foram também feitas em ambos: rio principal e lago.

Cerca de uma semana foi gasta num local no rio Negro a cerca de $60 \mathrm{~km}$ acima da confluência com o Solimões. O barco ficou ancorado na margem leste, próximo à boca do afluente leste, rio Cuieiras. A maioria das coletas foi feita no rio Cueiras e nos pequenos afluentes que encontravam ao longo do seu curso inferior (Fig. 2d).

O rio Solimões na boca do canal do lago Janauacá é caracterizado pela água marromclaro, de aluvião, fluindo a $6-8 \mathrm{~km} / \mathrm{h}$. Quando a água ficava no seu nivel mais baixo, a margem atingia cerca de 4 metros de altura, com um ângulo de cerca de $30-45$ graus. Altos capins cobriam a margem, do seu topo à marca da água baixa; árvores não eram numerosas nem estavam densamente agrupadas. Ao longo do canal entre o lago Janauacá e o Solimões, a margem atingia do muito íngreme até o quase plano; durante a cheia, muitas das áreas das margens baixas podiam ser completamente inundadas. Havia pedaços de terreno de florestas secundárias densas nas áreas acima da cheia (Fig. 2c). Muitos córregos pequenos fluiam no canal do Janauacá (Fig. 2b) e esses foram áreas de abundantes coletas, parcialmente por causa dos peixes aí grupados de manhã cedo e parcialmente por causa das margens brandamente inclinadas que permitiam que a pesca com rede fosse relativamen. te fácil.

$\mathrm{Na}$ área imediata ao ancoradouro do barco, não havia habitações, mas havia cerca de 20 casas ao longo do canal do lago do Janauacá e muito mais no próprio lago. A agricultura era evidente mas não generalizada na área e uma pequena olaria ficava situada no canal do Janauacá. A influência da população local sobre o lago, o rio e a foz parecia ser mínima, limitada na maior parte pelo labor de fertilização e, naturalmente, pela pescaria inevitável.

O habitat no rio Negro e rio Cuieiras era bastante diferente da do rio Solimöes. O rio Negro tem água "preta" e de fluxo muito mais lento $(2-4 \mathrm{~km} / \mathrm{h})$ do que o do Solimões. As margens do rio eram menos escarpadas do que as do Solimões, apresentando aspecto ora 


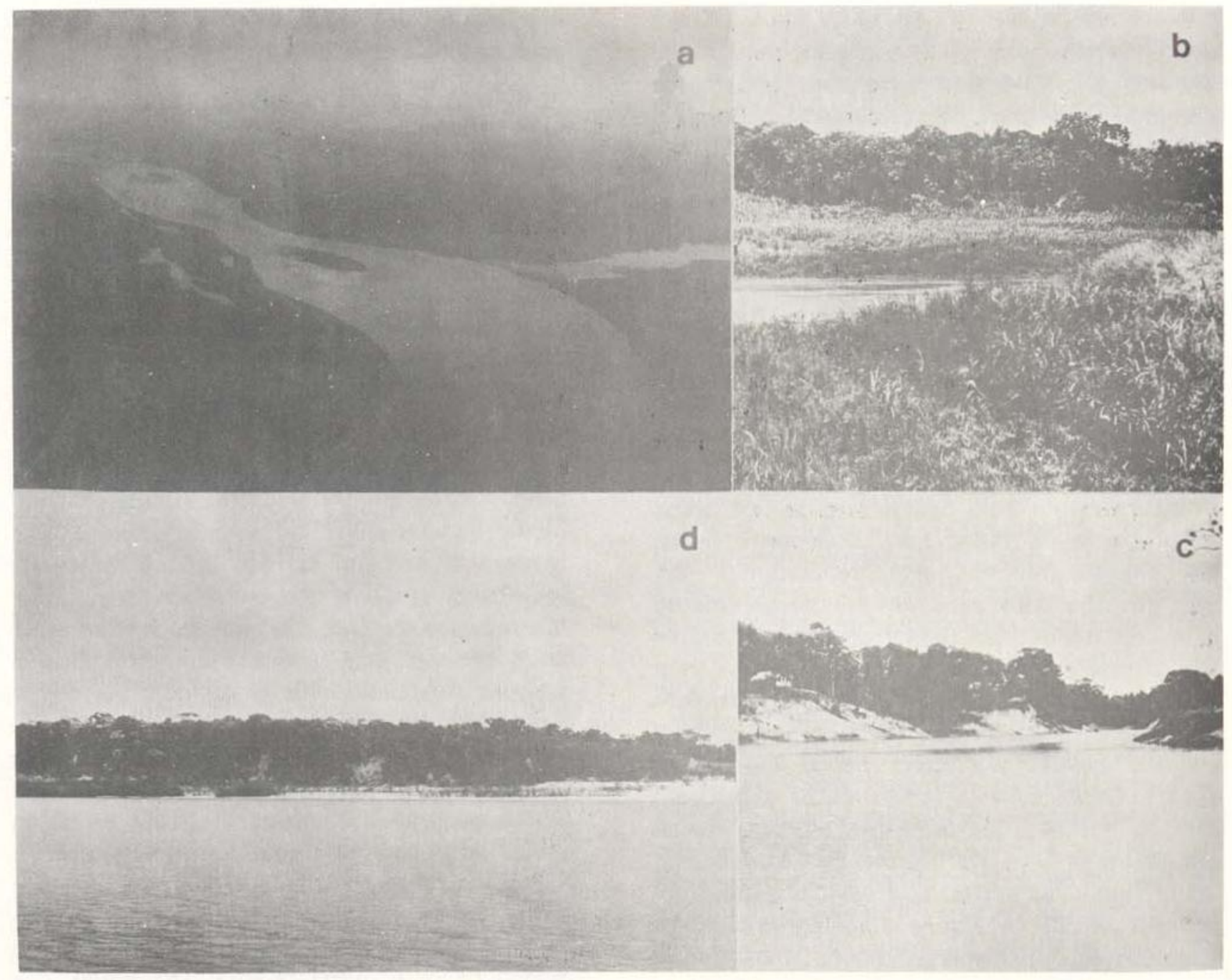

Fig. 2 - Alguns habitats representativos da Amazônia Central: a) rio Solimöes próximo a Tefé; b) paraná do Janauacá e igapó; c) paraná do Janauacá com casaș localizadas na terra firme; d) Local de coleta do rio Cuieiras, notem-se algumas destruiçōes de florestas pelo homem.

arenoso ora rochoso. A floresta nessa área era menos modificada pelo homem e multo mais densa do que na área do Solimões. O rio Cuieiras tinha muitos córregos pequenos (igarapés) alimentando desde a sua boca até os limites de nosso levantamento, a cerca de 5 $\mathrm{km}$ acima. Esses pequenos córregos tinham um fluxo muito mais lento e baixas densidades de peixes.

As densidades de populaçãa humana no rio Negrỏ/rio Cueiras eram muito mais baixas do que as no rio Solimőes; a agricultura era limitada ao tipo corte-queima (predatório).

\section{OS PEIXES}

Tendo descrito alguns elementos básicos do ecossistema aquático da Amazônia Central, gostaríamos agora de dar uma visão dos peixes amazônicos. Essa região apresenta um excelente local experimental para o biólogo comparativo e bioquímico dada a natureza de sua ictiofauna; ela tem um representante das pirambóias (Lepidosiren) antigas, vários membros de um grupo muito velho de teleósteos (Osteoglossidae), um bem restrito e altamente bem sucedido grupo de teleósteos que tem evoluído numa maneira "explosiva" (Ostario- 
physi), além de alguns peixes altamente evoluídos e avançados, tais como os ciclídeos e Synbranchus (Acanthopterygii) .

O objetivo deste artigo é dar alguma idéia da magnitude e diversidade da ictiofauna bem como algumas informações gerais sobre as relações evolucionárias entre os maiores grupos de peixes da Amazônia. Uma atenção primordial será dada à discussão das famílias de peixes com coletas representativas no "Alpha Helix". Essa informação será precedida, con tudo, por uma breve advertência, na forma de uma discussão do atual nível de conhecimento sobre a identificação de espécies e hipóteses das relações evolucionárias da maioria dos peixes neotropicais, e as dificuldades resultantes para o biólogo comparativo.

A habilidade técnica para sondar a bioquímica, hemoglobina, química respiratória e outros aspectos fisiológicos e bioquímicos dos peixes neotropicais ultrapassa longe nossa atual capacidade de apresentar hipóteses razoáveis da relação filogenética ou mesmo dar nomes aos peixes focalizados. De fato, de acordo com autores recentes (Böhlke et al., no prelo) o nível de conhecimento sobre a identidade e relações dos peixes sul-americanos é quase equivalente ao conhecimento da ictiofauna norte-americana, há um século. Quando se percebe que mesmo hoje, quase $10 \%$ da fauna de peixes norte-americanos de água doce continuam sem classificação (Jenkins, 1976) torna-se claro que uma quantidade enorme de trabalhos deve ser feita antes que os biólogos sistemáticos sejam capazes de fornecer a biólogos comparativos, ecólogos e outros pesquisadores os tipos de informaçöes que na América do Norte são tidas como definitivas, isto é, os nomes dos peixes, filogenias razoavelmente boas e classificaçöes e, pelo menos, algum conhecimento da sua história natural.

Todos os membros da expediçăo da Fase IV sentiram a frustração de trabalharem com peixes aos quais nenhum nome específico podia ser aplicado e, às vezes, até mesmo nomes genéricos eram incertos ou de pequeno significado filogenético. Embora a frustraçảo permanecesse, talvez sua intensidade pudesse ser aliviada se as razōes das dificuldades de identificação fossem entendidas. Como será evidente, na discussão abaixo, a fauna de peixes amazônicos é imensa, somando em milhares de espécies (muitas vezes a magnitude da americana). Muitas dessas espécies, talvez mais de 30 por cento, não são descritas, e muito mais são conhecidas com certeza, somente pelos espécimes originais descritos. Um grande número de espécies foi descrito com novos métodos, mais modernos que os anteriormente usados, e investigadores antigos da América do Norte e Europa perceberam a imensidade da fauna tropical. Como resultado, é virtualmente impossível identificar muitos dos peixes sul-americanos pela literatura ou mesmo pelas novas coleções de referência de alguns museus. Em vez disso, os espécimes de tipo original devem ser examinados (quando eles existem), sendo muitas vezes uma tarefa de custo e trabalho enormes. Lamentavelmente, a dificuldade e a despesa de fazer coletas e o recurso limitado para armazenagem de longa duração e manutenção prejudicam o índice de progresso de nosso conhecimento da fauna de peixes.

Outros fatores que dificultam a identificação de espécies devem ser mencionados (vide Böhlke, et. al., no prelo, para maiores informaçōes). Isso inclui a evolução explosiva em muitos grupos desses peixes (por exemplo, vários gêneros incluem 100 ou mais espécies), a evolução complexa de muitas características morfológicas levando à confusão sobre a delineação de limites genéricos, e muita evolução convergente o redutiva. Assim, mesmo as mais fundamentais e talvez as mais simples tarefas da biologia sistemática, a nomenclatura e catalogação da fauna é um problema sério e de longa duração.

O outro aspecto da biologia sistemática moderna, tão importante para biólogos comparativos ccmo identificação de espécies, é a tarefa de supor relações evolucionárias (filogenéticas) e a apresentação de classifica. ções que representam aquelas relações. Por causa das complexidades evolucionárias mencionadas acima, a criação e teste de hipóteses da filogenia nos peixes sul-americanos estão na sua infância. A maioria das classificações desses peixes, aos níveis genéricos e até mesmo de famílias, é inteiramente tipológica e re- 
flete graus evolucionários gerais mais do que relações genealógicas. Categorias superiores de peixes são menos tipológicas, pelo menos entre os grupos referidos neste trabalho.

A importância de um conhecimento das linhagens genealógicas pode talvez ser melhor enfatizada pela menção de enorme períodos de tempo entre as origens de maiores grupos de peixes estudados pelos cientistas da Fase IV. Por exemplo, a pirambóia, Lepidosiren (Subclasse Sarcopterygii) dividia um ancestral comum com os outros peixes estudados na Fase ${ }^{*}$ IV, há 350 milhões de anos, e tinha tido uma história independente desde aquele tempo. $\mathrm{Na}$ realidade, em termos de relações genealógicas, as pirambóias são mais estritamente relacionados ao Homo sapiens, como descendentes de peixes sarcopterígeos, do que a quaisquer outros peixes viventes, com exceção de Latimeria, o celacanto. O pirarucu e o aruanã (Superordem Osteoglossomorpha) dividiam um ancestral comum com os caracóideos e o bagre (Superordem Ostariophysi) e com os ciclídeos e "halfbeaks" (Hemiramphidae, Superordem Acanthopterygii) há cerca de 200 milhões de anos, durante a era dos dinossauros. O ancestral comum dos ostariofíseos e acantopterígeos, por sua vez, viveu há cerca de 160-190 milhões de anos e esses dois grupos têm evoluído independentemente desde então. Em vista desses longos períodos de tempo, as semelhanças entre esses grupos de peixes podem, na realidade, ser mais surpreen. dentes do que as diferenças. Presumivelmente o habitat aquático colocou certas limitações na forma do corpo e função, selecionando por mecanismos similares, a fim de que agissem de acordo com um meio ambiente similar. Não obstante as similaridades gerais na aparência, é importante para o biólogo comparativo estar ciente dessa história evolucionária e examinar resultados da pesquisa de sua perspectiva. Quando, por exemplo, compara-se o sangue de Lepidiosiren, a pirambóia com aquele do caracoídeo de respiração aérea, Hoplerythrinus, deve-se ter em mente que 350 milhōes de anos de evolução independent'e separam essas duas formas, urha extensão de história independente mais longínqua do que aquela que separa o homem dos lagartos.
Uma palavra sobre a filogenia e classificação usada neste trabalho é o que se segue. A década passada foi um tempo de grande mudança nos conceitos de classificação e filogenia, com relação aos métodos e à filosofia. Conceitos atuais das relações dos grupos superiores de peixes diferem daqueles da década passada, mas agora estamos num período de fluxo de opiniōes visando a essas relaçōes como sendo largamente variadas. O que adotamos aqui, pelo menos para os teleósteos, é a classificação de Greenweed et al. (1966).

Nas descrições abaixo, os maiores grupos - superordem acima - são discutidos no possível sentido da origem filogenética: dentro desses grupos, nenhuma ordenação filogenética é inferida, além de declarações explícitas sobre as relações que são feitas. Em algumas instâncias, uma família inteira pode ser referida em poucas palavras; em outras, gêneros e espécies são discutidos em mais minúcias. As famílias, gêneros, e, quando possível, espécies representadas nas coletas do "Alpha Helix", Fase IV, såo listadas na classificação da Tabela I.

O grupo de peixes mais velho, representado nas águas amazônicas é o dos cartilaginosos, classe Chondrichthyes, incluindo tubarões e arraias. Uma família de tubarōes e duas famílias de arraias, incluindo uma família de peixe-serra, ocorrem na Amazônia. Os únicos elasmobrânquios coletados pela Fase IV foram arraia-lixa (Dasyatidae) de água doce, gênero Potamotrygon (Postamotrygonidae, Fig. 3a) . Esses peixes eram comuns no canal entre o lago de Janauacá e o rio Solimões e cerca de quatro espécies foram apanhadas lo gênero necessita de revisão e a identificação da espécie não pode ser feita com confiança; a família atualmente está sob estudo pelo $\mathrm{Dr}$. Hugo P. Castello). O maior espécime capturado pela Fase IV pesava cerca de $5 \mathrm{~kg}$ e media um pouco menos que meio metro de diâmetro. Esses eram peixes que vivem no fundo e que se enterram nos sedimentos lamacentos e macios, representando um perigo para os vadeadores. A ferroada é bastante dolorosa de demorada cicatrização (cf. Halstead, 1970, para uma revisão de leitura pertinente). Presumivelmente esses peixes, como muitos de seus 
parentes de água salgada, se alimentam de invertebrados que vivem nos substratos lamacentos ou arenosos.

A pirambóia, Lepidosiren paradoxa (lepidosirenidae Fig. 3b) é um membro de um grupo antigo de peixes ósseos, a Subclasse Sarcopterygii, ou peixes de barbatanas lobadas. As pirambóias foram difundidas e com sucesso desde o Devoniano até o fim do Triássico, hả cerca de 136 milhões de anos, mas somente três gêneros ocorrem hoje. Um gênero e espécie, Neoceratodus forsteri, é encontrado hoje na Austrália, e várias espécies de Protopterus ocorrem na Africa.

Lepidosiren e Protopterus são ambos menciodos por cavarem tocas e estivarem durante os períodos de seca da água (Carter \& Beadle, 1930). Lepidosiren é encontrado na Amazônia em alagados, lagoas e também em lagos, embora usualmente só próximo às áreas da margem, onde condições de alagados possam existir. Esses peixes são relativamente grandes (acima de 1,2 m), de movimentos lentos e, de acordo com Carter \& Beadle (1930), provavelmente, alimentam-se, primordialmente, de plantas aquáticas quando adultos.

Os Osteoglossidae ou peixes de língua óssea, são também um grupo antigo com pou. cas espécies existentes. Esse e todos os grupos seguintes fazem parte da subclasse Actinopterygii, ou peixes de "barbatana raiada". Dois gêneros e três espécies de Osteoglossidae ocorrem na Amazônia - Arapaima gigas, Osteoglossum bicirrhosum e $O$. ferreirai. Todas as três espécies revelam cuidados com ninhada. Esses peixes foram de especial interesse à Fase IV, visto que Arapaima (Fig. $3 b)$ é um dos maiores peixes de água doce do mundo, mencionado como tendo $4 \mathrm{~m}$ de comprimento e $200 \mathrm{~kg}$ de peso (Gudger, 1943, mas cf. Migdalski, 1957). Espécimes de 2,5 $\mathrm{m}$ de comprimento eram razoavelmente comuns e mantinham uma pesca comercial (apesar do excesso de sua pesca, evidente no Brasil e Peru). Arapaima é primariamente um piscívoro que nada lentamente ou fica à espera de suas presas; ele é encontrado muito comumente em certos tipos de lagos.

Osteoglossum bicirrhosum (Fig. 3c) que atinge um metro de comprimento, é um nadador vagaroso, extremamente gracioso e se alimenta de insetos, peixes e outros pequenos vertebrados. Os coletores da Fase IV encontraram $O$. bicirrhosum em grandes cardumes, próximos às pequenas bocas de córregos no canal do lago Janauacá, particularmente de manhã cedo. Quando surpreendidos, os peixes tentaram escapar dando enormes saltos no ar.

Osteoglossum choca a sua ninhada na boca. Como Arapaima, é um importante peixe comercial.

A Clupeidae (arenque) é representada, nos achados do "Alpha Helix" pela llisha amazonica. A llisha está distribuída nas regiões tropicais do Atlântico, Pacífico e Oceano Indico e nos maiores rios da Bacia Amazônica. Espécimes de I. amazonica capturados pela Fase IV eram relativamente grandes, com aproximadamente $35-40 \mathrm{~cm}$ de comprimento. Típica da família na forma e cor, essa espécie é um peixe argênteo fortemente achatado, parecendo muito com uma sardinha enorme. Roberts (1972) menciona que os clupeídeos amazônicos tendem a alimentar-se de peixes mais do que de plancton como o faz a maioria dos membros da família.

Os Ostariophysi (atualmente colocados ao nível de superordem) é o grupo de peixes de água doce predominante na América do Sul, com doze familias de caracoídeos (caracideos, Tetras), quatro famílias de gimnotóides (peixes elétricos) e quatorze famílias de siluróides (bagres). É provável que os ostariofíseos na América do Sul evoluíram de alguns ancestrais pouco comuns num ecossistema relativamente pouco utilizado, com uma radiaçăo resultante "explosiva" em quase todos os nichos de água doce imagináveis. Esse fenômeno evolucionário iguala ou ultrapassa qualquer outra radiação da evolução de vertebrados ca. racoídeos sozinha, que tem sido considerada como muito mais espetacular do que a dos marsupiais da Austrália (Weitzman, 1962). O Ostariophysi é, de fato, o grupo de peixes de água doce dominante no mundo. Os fatores contribuintes para seu sucesso não são bem estendidos, mas a simples projeção da especialização morfológica, mantida em cơmum por todos os membros, é o aparato Weberiano, uma estrutura complexa consistindo primeiramente de costelas modificadas conectando a 
bexiga natatória ao ouvido interno. O apareIho Weberiano parece prover os ostariofíseos com maiores habilidade auditivas do que outros peixes.

Os caracoídeos (Subordem Characoidei) são considerados os mais especializados dos ostariofíseis neotropicais, uma vez que eles são menos modificados que os bagres ou gimnotóides na morfologia corpórea. Todavia, o âmbito de especializações dos caracoídeos em termos de estruturas tróficas e em termos de estratégias ecológicas e reprodutivas é verdadeiramente espetacular. Os caracoídeos, agora, ocupam nichos similares aos do "pike" (Esocidae), trutas, "minnows" (Cyprinidae), peixes-agulha, arenques e guarus (Cyprinodontidae), e também ocupam nichos não ocupados por outros peixes. A maior parte da evolução dos caracoídeos está centrada em volta de especializações tróficas, e a maior parte das famílias é definıda, baseada nas estruturas alimentares. Enquanto nenhuma pesquisa tem sido capaz de mostrar como ou quando essas especializações são realmente usadas, os que trabalham com os caracoídeos têm feito hipóteses de que os ancestrais pouco primitivos dos caracoídeos modernos condicionaram-se a alimentar-se de maneira que minimizaram a competição com seus parentes, e que uma evolução subseqüente tem acentuado essas especializaçöes. Esse fenômeno de separação ecológica (divisão de habitat) é pouco compreendido.

A maior família dos caracoídeos, Characidae, consiste, na maior parte, de peixes generalizados de tamanho relativamente pequeno. Muitos são familiares como o colorido Tetra do comércio de aquários. Uma vez que os investigadores da Fase IV estavam interessados primeiramente em peixes grandes, somente oito gêneros caracídeos foram examinados. A maioria deles mais especializados do que o comum da família.

Chalceus é um caracídeo ativo e de cardume; é um peixe alongado e atinge cerca de $25 \mathrm{~cm}$ de comprimento. A característica mais distintiva desse peixe é que as escamas acima da linha lateral são consideravelmente maiores do que as de baixo. As espécies de Charax são peixes bons nadadores e de cardumes e que atingem cerca de $15 \mathrm{~cm}$ de comprimento. O Charax tende a nadar na posição de cabeça baixa, alimentando-se de invertebrados que vivem no fundo, particularmente lavas de insetos aquáticos. Os espécimes de Charax testados pela Fase IV foram quase sempre apanhados ao longo das praias arenosas. Colossoma e Mylossoma são peixes proximamente aparentados; ambos são de corpos não achatados e são predominantemente vegetarianos na dieta. Os espécimes de Colossoma atingem comprimentos acima de $70 \mathrm{~cm}$ enquanto que os de Mylossoma atingem menos da metade desse tamanho; ambos os peixes, especialmente o último, são as maiores fontes de alimentos locais. Aparentemente Mylossoma nada em grandes cardumes; o autor observou pescadores locais pescando cerca de um mil em duas redes de arrastão, a cerca de 25 metros da margem do rio Negro, próximo a Manaus. Colossoma parece ocorrer em pequenos grupos. Ambos esses peixes são relativamente aparentados às piranhas carnívoras.

As piranhas (Serrasalmus, Fig. 3e) são peixes comuns na Amazônia Central e foram bem representados nas coletas da Fase IV. Os maiores espécimes foram coletados pela Fase IV nas águas abertas dos leitos dos rios principais e formações menores; espécimes pequenos foram apanhados próximo à margem, nas áreas graminosas. Esses peixes nadam em cardumes alimentando-se de outros peixes, invertebrados ou vertebrados terrestres, tantos quantos possam cair em seu domínio. Pouco dos fatos documentados sobre esses peixes são conhecidos mas as lendas são numerosas e impressionantes. Dizem que os maiores espécimes das maiores piranhas podem atingir um comprimento de $45-60 \mathrm{~cm}$ (Myers, 1972). Dada a quantidade testada pela Fase IV, deve esclarecer-se aqui que nosso conhecimento, da sistemática da piranha, é muito pobre. Um número de gêneros tem sido descrito mas todas as espécies de piranhas, provavelmente, poderiam ser colocadas no gênero Serrasalmus. A maioria dos estudos anteriores do grupo estava limitada pela falta de grandes coletas de espécimes em todos os estágios de crescimento e pela falta de informações sobre a feição de vida. A determinação do número de espécies testadas pela Fase IV tem sido difícil. Prova- 
velmente quatro ou mais espécies estão enfocadas, mas os critérios que foram usados em "espécies" separadas, no campo, foram consideradas insustentáveis quando um número suficiente de espécimes foi examinado - nossas "espécies" começaram a nivelar-se numa só.

As espécies de Tetragonopterus são caracídeos muito generalizados, de corpo não achatado, que atinge cerca de $15 \mathrm{~cm}$ de comprimento. Peixes de cardume e nadadores potentes, os Tetragonopterus foram coletados pela Fase IV ao longo da margem arenosa do rio Solimões.

Triportheus é um peixe alongado com uma região do "torax" em forma de quilha profunda e barbatanas peitorais muito alargadas; os membros desse gênero atingem cerca de $20 \mathrm{~cm}$ de comprimento. Espécimes de Triportheus foram vistos nadando muito rapidamente com a região anterior fora da água, usando as barbatanas peitorais como "asas". Os Triportheus fo. ram apanhados pela Fase IV em águas abertas do Paraná do Janauacá.

A Erythrinidae é uma pequena família de peixes caracídeos predadores que são considerados como sendo muito primitivos (Roberts, 1969). Duas espécies de eritrinídeos, muito, relacionados, foram de particular interesse aos investigadores da Fase IV uma vez que Hoplerythrinus unitaeniatus é um peixe de respiração aérea facultativa e o outro, Hopllas malabaricus não o é. Hoplias (Fig. 3f), um eficiente predador, é um peixe comum, largamente dispersado; ele é encontrado por toda a América do Sul tropical e sub-tropical e compōe uma percentagem muito alta de biomassa em muitas águas sul americanas (Bonetto et al., 1969) . Hoplias ocorre numa variedade de habitats de água rasa. Durante períodos de água baixa $\mathrm{e}$ em lagoas onde o conteúdo de oxigênio é baixo, indivíduos de Hoplias podem ser vistos descansando próximo à margem logo abaixo da superfície da água onde eles são capazes de utilizar as camadas superiores oxigenadas da água. Hoplerythrinus (Fig. $3 \mathrm{~g}$ ) embora nem tão espalhado nem tão numeroso quanto Hoplias, é, todavia, um peixe comum também. Quando o conteúdo de oxigênio de seu habitat aquático cai, Hoplerythrinus é capaz de subir à superfície e tomar o ar atmos- férico em sua bexiga natatória altamente vascularizada. Lowe-McConnell (1975) menciona que Hoplerythrinus tem sido notado movimentando-se por terra; certamente, o peixe é capaz de manter-se verticalmente e se locomover rapidamente sobre o convés do barco usando as barbatanas pares e movimentos sinuosoidais (observação pessoal). Hoplias atinge cerca de $60 \mathrm{~cm}$ de comprimento, Hoplerythrinus cerca de metade desse tamanho.

A Cynodontidae é uma outra pequena família caracoídea de peixes predatórios mas, neste caso, os peixes são altamente especializados. Rhaphiodon e Cynodon (Fig. 3h) foram examinados durante a Fase IV. Os membros da Cynodontidae são bastante ativos e tendem a ficar próximos à superfície em áreas abertas de grandes cursos d'água. $\mathrm{O}$ aspecto mais notável da sua morfologia é a presença de dois longos dentes, como caninos, na mandíbula inferior: quando a mandíbula está fechada esses dentes se inserem em cavidades profundas no crânio. Alguns indivíduos de Rhaphiodon atingem pelo menos $69 \mathrm{~cm}$ (Schultz, 1950) Cynodon atinge cerca de $40 \mathrm{~cm}$.

A Prochilodontidae é uma pequena família de caracoídeos especializados e qua se alimentam de lodo. Cerca de trinta espécies de malor gênero, Prochilodus, têm sido descritas e a sistemática do gênero necessita de revisão. Prochilodus é um importante peixe na Amazônia por seu uso freqüente na alimentação. As espécies de Prochilodus atingem cerca de $50 \mathrm{~cm}$. Quando adultos, esses peixes usualmente agrupam-se em massa em águas abertas de lagos e rios; eles são conhecidos por empreenderem extensas migraçōes para a desova (Mago-Leccia, 1972).

Prochilodus têm uma grande boca, evertível e pequenos dentes e aproveitam uma fonte de alimento aparentemente ilimitada; elas nadam sobre o fundo comendo lodo e presumivelmente digerem seu conteúdo orgânico para alimentaçăo (Knoppel, 1970; Marlier, 1968).

A Curimatidae é uma família caracoídea de peixes que se alimentam de areia e detritos, na qual Curimatus (Fig. 3i) foi examinado pelos investigadores da Fase IV. As espécies de Curimatus são desdentados; como Prochilodus, elas são nadadoras ativas que se agrupam pró- 

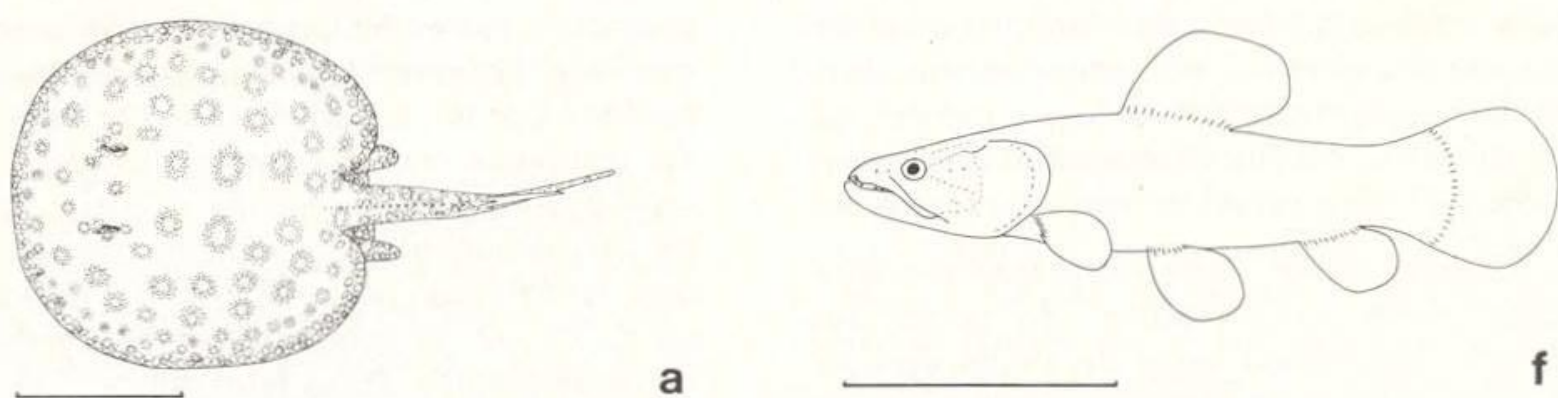

a
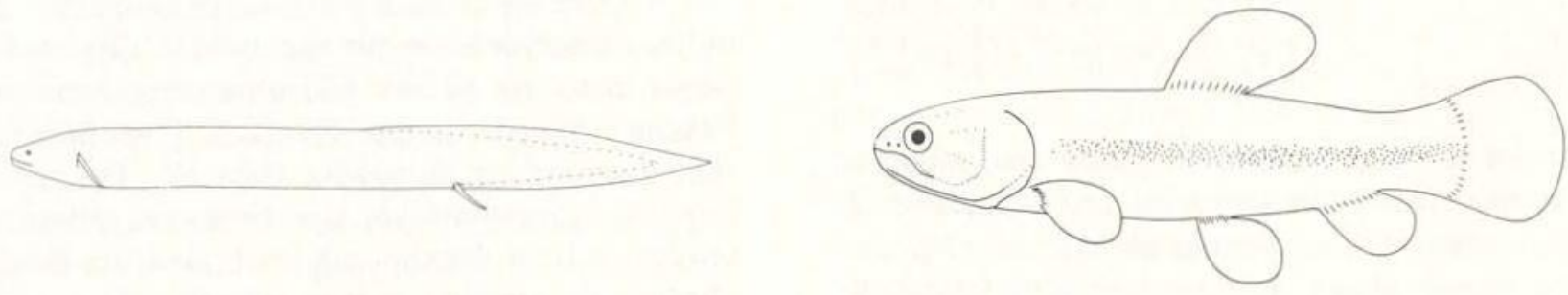

b

g
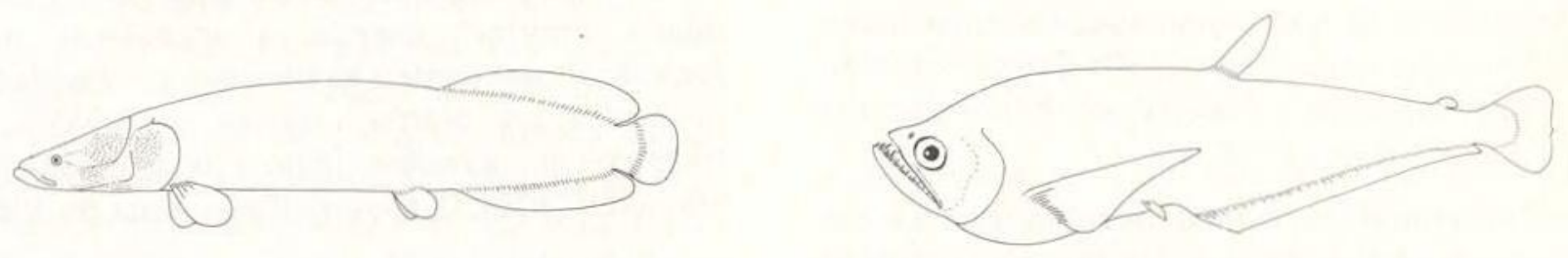

C

h
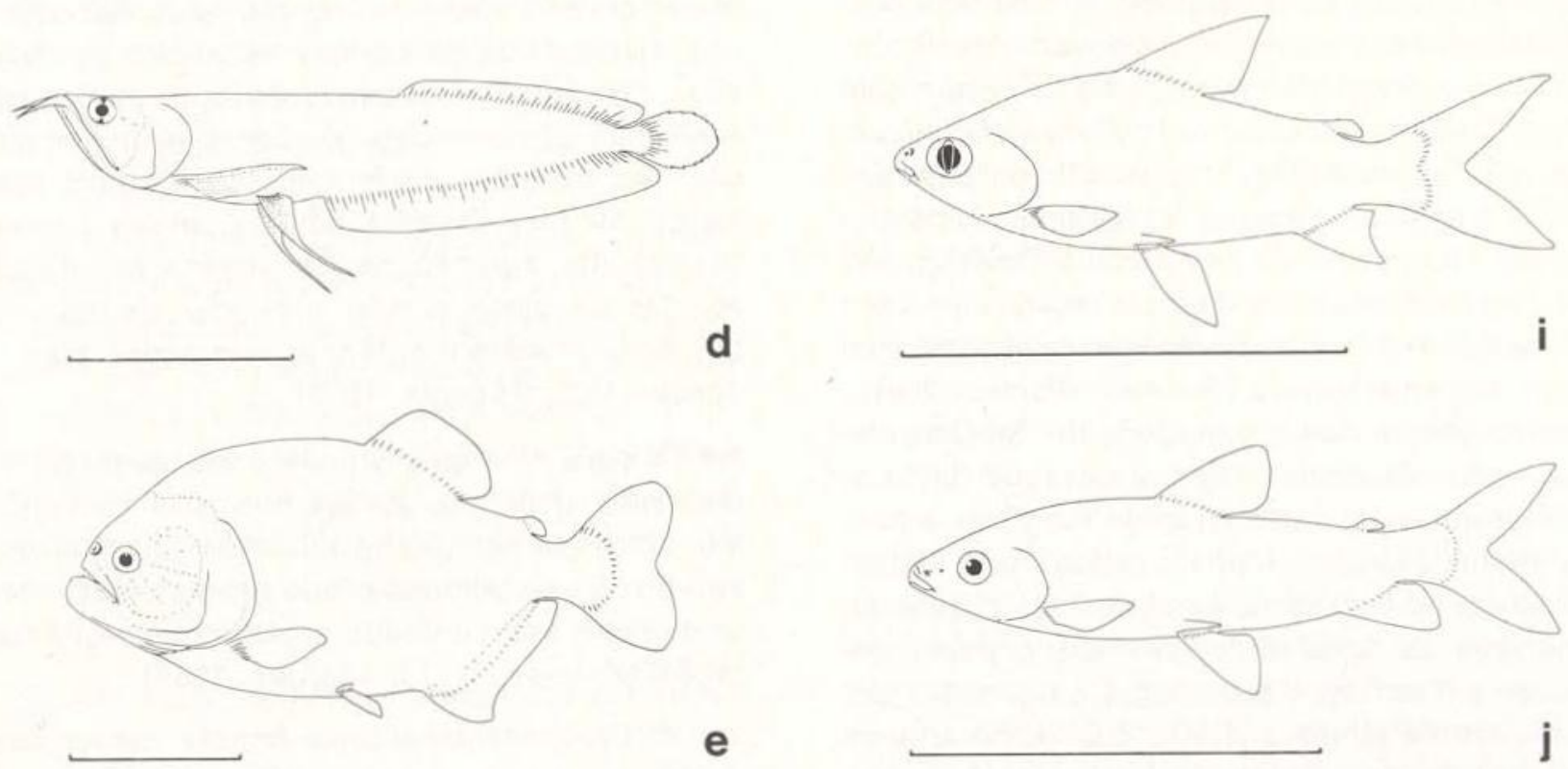

Fig. 3 - Exemplos relacionados de peixes amazonenses: a) Potamotrygon sp.; b) Lepidosiren paradoxa; c) Arapaima gigas; d) Osteoglossum bicirrhosum; e) Serrasasalmus sp.; f) Hoplias malabaricus; g) Hoplerythrinus untaeniatus; h) Cynodon gibbus; i) Curimatus sp.; j) Leporinus sp. Linha $=10 \mathrm{~cm}$. 
ximo ao fundo, em águas abertas. As espécies de Curimatus atingem cerca de $15 \mathrm{~cm}$ de comprimento.

A Anostomatidae é uma pequena família de peixes caracoídeos relativamente especializados que presumivelmente usam seus dentes em forma de pinça para selecionar alimentos. Leporinus (Fig. 3j).

Schizodon e Rhytoodus são os três gêneros apropriados a essa discussão aqui. Todas as espécies nesses gêneros são nadadores potentes e todos os espécimes foram capturados em águas abertas, ou em grandes córregos ou nos leitos do rio principal. Membros dessa família são comuns em mercados de peixes, na área. Os espécimes grandes atingem cerca de $40 \mathrm{~cm}$.

Hemiodontidae coletados pela Fase IV incluem espécies de gênero Hemiodus (Fig. 4a) e Micromischodus. Hemiodontideos são peixes de cardumes que são aerodinâmicos na forma e nadadores extremamente hábeis. Eles são encontrados nos maiores canais e provavelmente no rio principal. Quando capturados por uma rede, esses peixes freqüentemente dão saltos surpreendentes fora da água em pequenos grupos. Os adultos atingem cerca de $30 \mathrm{~cm}$ de comprimento. Todos os Hemiodus adultos têm mandíbulas inferiores sem dentes minúsculos e pedicelados na mandíbula superior; os Micromischodus adultos também têm dentes pequenos na mandíbula inferior. Ambos os gêneros têm boca bastante especializada e provavelmente são seletivos na alimentaçăo, tomando seu alimento dos detritos ou dos sedimentos do fundo. Pelo menos um gênero de Hemiodontidae. Anodus, é um filtrador especializado.

O segundo maior dos ostariofíseos da América do Sul consiste de peixes da subordem Gymnotoidei, um grupo que se suspeita dividir um ancestral comum com os caracoídeos. Os gimnotóides ou peixes elétricos são alongados na forma e são capazes de nadar ou para frente ou para trás com igual facilidade usando movimentos ondulatórios de suas longas barbatañas anais. Os gimnotóides transmitem pequenos sinais elétricos que são usados na comunicação intraespecífica (vide por exemplo, Hopkins, 1974) e também, presumivelmen- te, na localização do alimento; há uma extensa literatura na eletrogênese e eletrorrecepção desses peixes (cf. Bennett, 1970, 1971a,b). A maioria dos gimnotóides são crepusculares ou noturnos, deixando suas tocas diurnas ou outros lugares de esconderijo para se alimentar no leito dos córregos e retornando à mesma toca ao alvorescer (Steinbach, 1970).

Quatro famílias de gimnotóides são reconhecidas pelos ictiólogos e a Fase IV examinou representantes de cada uma. Electrophorus electricus, a famosa "enguia" elétrica, é o único membro da Electrophoridae e é o único gimnotóide capaz de uma poderosa descarga elétrica. Ele e Gymnotus carapo (Gymnotidae) são, ambos, habitantes de águas lentas, muitas vezes estagnadas; ambos também têm resplração aérea. Nessas duas famílias, o órgão elétrico é derivado do tecido muscular e a taxa de descarga é baixa, cerca de 200 a $500 \mathrm{cps}$. Electrophorus provavelmente é, primariamente piscívoro e atinge cerca de um metro de comprimento. Gymnotus se alimentam, na maioria das vezes, de larvas de insetos (Knöppel, 1970) e atinge menos de $30 \mathrm{~cm}$ de comprimento.

Uma terceira família gimnotóide, a Apteronotidae, está representada nas coletas de Fase IV por uma única espécie de Apteronotus. A maioria dos membros desse gênero está em movimento, em águas bem aerificadas e alimentam-se primariamente de larvas de inseto aquáticos. Algumas espécies apteronotídeas desenvolvem rostros alongados. Os apteronotídeos emitem descargas de alta freqüência elétrica $(1.000-1.200 \mathrm{~Hz})$ de seus órgãos elétricos derivados neuralmente. A maioria das espécies de Apteronotus tem menos de $30 \mathrm{~cm}$, quando adultos.

$\mathrm{Na}$ quarta família gimnotídea, Rhamphichthyidae, os três gêneros foram Eigenmannia, Sternopygus e Rhamphichthys (Fig. 4b). Os membros dessa família têm corpos que afilam posteriormente, algumas vezes a um longo filamento caudal, mas falta a barbatana caudal. A área caudal contém o órgão elétrico principal; órgãos elétricos acessórios são conhecidos em algumas espécies e estão localizados na cabeça. As espécies de Eigenmannia são translúcidas em vida, atingem um comprimen- 
to máximo de cerca de $30 \mathrm{~cm}$, e têm rostros relativamente curtos ou muito curtos. Sternopygu's macrurus é marrom escuro, atinge quase um metro de comprimento e também tem. rostro curto. Rhamphichthys, notável na sua aparência, atinge mais de um metro de comprimento e tem um rostro longo e tabular. Várias espécies desse gênero têm sido descritas, mas a maioria dos autores usualmente reconhecem somente uma espécie, morfologicamente variável (Ellism, 1913). Os achados de Fyhn et al., 1978, (neste volume) indicam uma correspondência entre padrões de hemoglobina, padrão de cor e comprimento do rostro, sugerindo a existência de mais uma espécie e uma necessidade de reavalização crítica de gênero. Rhamphichthys tem uma descarga de freqüência muito baixa. Supõem-se que passam as horas da luz diurna enterrados nos sedimentos do fundo do córrego ou do rio. Baseado no pequeno tamanho da boca, uma dieta consistindo primariamente de larvas de insetos aquáticos, é provável. Vide Schwassman (1976) para informações sobre a sistemática e ecologia do proximamente aparentado Gymnorhamphichthys.

Siluriformes, os bəgres, é o terceiro grupo ostariofíseo na América do Sul e está entre os peixes mais espectaculares na Amazônia, na forma e hábitos de vida. Seu tamanho e hábitos variam do minúsculo candiru, tricomicterídeo, com cerca de $2,5 \mathrm{~cm}$ de comprimento, que parasitam as brânquias de peixes maiores, aos gigantes pimelodídeos Brachyplatystoma que atingem quase $3 \mathrm{~m}$ de comprimento, cerca de $90 \mathrm{~kg}$ de peso e têm o hábito de viver no fundo, típico da ordem (Gudger, 1943). Características da ordem Siluriformes e presentes na maioria, mas não em todos, bagres sul americanos são as várias formas características. $\mathrm{O}$ primeiro raio da barbatana dorsal e cada barbatana peitoral usualmente formam espinhos razoavelmente proeminentes; estes podem ser eretos e em tufos, formando um artifício protetor triangular espinhoso. Um crânio densamente ossificado usualmente proporciona maior proteção. As famílias doradídea (Fig. 4c), calictídea (Fig. 4d) e loricarídea (Fig. 4e), de bagres, são também armadas de chapas ósseas, em padrões distintos para cada família; presumivelmente tal couraça, pelo menos no caso das duas últimas famílias, diminui suscetivelmente a dissecação bem como a predação. Também características da maioria dos membros Siluriformes, mas não peculiar a eles, é a posse de barbilhões, a presença de pequenos mas numerosos dentes que permitem uma variedade de estratégias alimentares, e hábitos de vida nas profundidades.

Muitos dos nichos ecclógicos ocupados pelos bagres são essencialmente similares aos mantidos por muitos caracoídeos, mas os bagres usualmente são crepusculares e alimentam-se enquanto seus correlatos diurnos são inativos. Alguns bagres, contudo, ocupam com sucesso nichos diurnos, por exemplo, o filtrador Hypophthalmus. As interações entre a "fauna diurna" e a "fauna noturna" das águas tropicais são complexas e pouco conhecidas.

Se relações filogenéticas entre famílias de bagres são muito pouco conhecidas e deve esperar-se que os gêneros sejam elevados e rebaixados para o grau de família ou terão que mudar de família para outra à medida em que nosso conhecimento aumenta. Quarenta famílias de bagres, conhecidas atualmente, ocorrem nas águas doces da América tropical, das quais todas, exceto a essencialmente marinha Ariídae são endêmicas. Oito famílias foram estudadas pela Fase IV.

Membros da Doradidae (Fig. 4c) são prontamente distinguíveis pela fileira de placas ósseas, que usualmente comportam farpas proeminente, estendendo-se ao longo das laterais do peixe; além disso, os raios espinhosos das barbatanas peitoral e dorsal são normalmente serrilhados. Essa família diversa e próspera está representada, na Fase IV, por nove gêneros (cf. Tab. I). As espécies de Pseudodoras crescem o bastante para o comercio de peixes - quase um metro de comprimento e por volta de $8 \mathrm{~kg}$ de peso - mas a maioria dos doradídeos é consideravelmente menor, medindo cerca de $20 \mathrm{~cm}$ de comprimento. Muitos dos doradídeos menores (por exemplo, Anadoras) são mais fortemente encouraçados do que os membros maiores da família e têm barbatanas peitoral e dorsal espinhosas mais proeminentes e fortemente serrilhadas. Os doradídeos são peixes que nadam vagarosamente, vivem no fundo e que se alimentam primariamente de larvas de insetos 
aquáticos (Marlier, 1966). As espécies maiores, tais como membros de Pseudodoras, foram capturados por pescadores. locais nas águas profundas dos leitos do rio principal; doradídeos menores foram capturados em áreas marginais.

A Auchenipteridae é uma pequena família representada aqui por Auchenipterus e Trachycorystes. Estes são peixes pequenos e ativos com cerca de $15 \mathrm{~cm}$ de comprimento, que se escondem em toros ou entulhos dos córregos durante as horas claars do dia e se alimentam à noite. Auchenipteridae normalmente são peixes de cardumes e, de acordo com Saul (1975), preferem águas rápidas que fluem sobre fundos arenosos, particularmente próximas aos depósitos de areia da linha da margem. Ele descobriu que insetos terrestres predominavam na dieta do gênero em foco, Centromochlus. Durante a Fase.IV do "Alpha Helix", numerosos espécimes de Trachycorystes foram visíveis próximos, todas as noites, nadando na correnteza de $8 \mathrm{~km} / \mathrm{h}$ do rio Solimões sob a luz da popa do barco.

A Pimelodidae é a segunda maior família de bagres neotropicais em número e espécie, com cerca de 250 atualmente descritas. Um maior número de espécies de peixes grandes está incluído na Pimelodidae do que em qualquer outra família de peixe sul americano. Notáveis entre esses são os membros do gênero Brachyplatystoma (mencionado acima), Hemisorubim e Pseudoplatystoma. A maioria dos pimelodídeos são peixes muito ativos e são grandemente piscívoros mas capazes de utilizar qualquer outro alimento substancioso, incluindo plantas e invertebrados. Embora a maioria das espécies tomem a maior parte do seu alimento dos fundos dos rios ou dos córregos, o alimento provavelmente é capturado em qualquer meio de sua existência. Essa necessidade de dieta relativamente não especializada pode ser uma razão para o fato de os pimelodídeos serem tão dispersos e numerosos. Alguns dos gêneros com mais espécies, particularmente Rhamdia e Pimelodus, têm sérias necessidades de revisão. Dez gêneros de pimelodídeos foram pesquisados pela Fase IV (vide Tabela I)

\section{TABELA I}

Classe Chondrichthyes

Subclasse Elasmobranchii

Ordem Rajiformes

Família Potamotrygonidae

Potamotrygon s.p. (4 espécies)

Classe Osteichthyes

Subclasse Sarcopterygii

Ordem Dipteriformes

Família Lepidosirenidae

Lepidosiren paradoxa

Subclasse Actinopterygii

Superordem Clupeomorpha

Ordem Clupeiformes

Subordem Clubeoidei

Família Clupeidae

Ilisha sp.

Superordem Osteoglossomorpha

Ordem Osteoglossiformes

Família Osteoglossidae

Osteoglossum bicirrhosum

Arapaima gigas

Superordem Ostariophysi

Ordem Cypriniformes

Subordem Characoidei

Família Characiddae

Chalceus sp.

Charax sp.

Colossoma sp.

Mylossoma sp.

Serrasalmus sp. (4 espécies examina-

das)

Tetragonopterus sp.

Triportheus sp.

Família Erythrinidae

Hoplias malabaricus

Hoplerythrinus unitaeniatus

Família Cynodontidae

Cynodon gibbus

Rhaphidon vulpinas

Família Prochilodontidae

Prochilodus sp.

Família Curimatidae Curimatus sp.

Família Anostamidae Leporinus sp.

Rhytiodus sp.

Schizodon sp.

Família Hemiodontidae Hemiodus sp. (3 espécies examinadas) Micromischodus sugillatus 
Subordem Gymnotoidei

Família Gymnotidae Gymnotus carapo

Familia Electrophoridae Electrophorus electricus

Família Apteronotidae Apteronotus sp.

Familia Rhamphichthyidae

Eigenmannia sp.

Rhamphichthys sp. (2 espécies ?)

Sternopygus sp.

Ordem Siluriformes

Familia Doradidae

Acanthodoras sp.

Anadoras sp.

Astrodoras sp.

Doras sp.

Hassar sp.

Hemidoras sp.

Opsodoras sp.

Pseudodoras sp.

Trachydoras sp.

Família Auchenipteridae

Auchenipterus sp.

Trachycorystes $\mathrm{sp}$.

Família Pimelodidae

Brachyplatystoma sp. (2 espécies exa-

minadas)

Hemisorubim sp.

Leiarius sp.

Phractocephalus hemiliopterus

Pimelodella sp.

Pimelodua sp.

Pinirampus sp.

Pseudoplatystoma sp.

Rhamdia sp.

Sorubim lima

Família Ageneiosidae

Ageneiosus sp.

Familia Hypophthalmidae

Hypophthalmus sp.

Família Cetopsidae

Cetopsis coecutiens

Familia Callichthyidae

Hopiosternum littorale

Familia Loricariidae *

Ancistrus sp.

Chaetostomus sp.

Hypostomus sp.

Loricaria $\mathrm{sp}$.
Loricaria cf. clavipinna

Loricariichthys acutus

Loricariichthys cf. maculatus

Loricariichthys sp. (não descrita)

Parahemiodon sp.

Pseudoloricaria sp.

Pterygoplichthys sp. (2 espécies exa-

minadas)

Spatuloricaria sp.

Sturisoma sp.

Xenocara sp.

Superordem Atherinomorpha

Ordem Atheriniformes

Família Belonidae

Potamorrhaphis sp.

Superordem Acanthopterygii

Ordem Synbranchiformes

Família Synbranchidae

Synbranchus marmoratus

Ordem Perciformes

Subordem Percoidei

Família Sciaenidae Plagioscion sp.

Familia Cichlidae Acarichthys heckelii

Acaronia nassa

Aequidens tetramerus

Astronotus ocellatus

Biotodoma cupido

Chaetobranchopsis orbicularis

Chaetobranchus flavescens

Cichla ocellaris

Cichla temensis

Cichlasoma bimaculatum

Cichlasoma festivum

Cichlasoma severum

Geophagus jurupari

Geophagus surinamensis

Pterophyllum sp.

Ordem Pleuronectiformes

Família Soleidae

Achirus sp.

Ordem Tetraodontiformes

Família Tetraodontidae

Colomesus psittacus

(*) - Um loricarídeo não identificável a gênero. Xenocara sp. experimentalmente identificado aqui, é o mesmo peixe referido como "Ancestrinae", espécie nāo identificada por Fyhn et al. (1978) e Powers et al. (1978), neste volume. 
A Ageneiosidae é uma pequena família de somente dois gêneros dos quais somente Ageneiosus (Fig. 4d) foi objeto de estudo. As espécies de Ageneiosus são hábeis nadadores, e atingem cerca de meio metro de comprimento. Somente dois barbilhões estão presentes e estes podem estar colocados em ranhuras, presumivelmente para aumentar a forma aerodinâmica. Ageneiosus provavelmente é um piscívoro.

A Hypophthalmidae contém um único gênero, Hypophthalmus (Fig. 4e), e especialistas discordam quanto ao número de espécies. Hypophthalmus é bastante característico, com um dorso oblíquo, quatro barbilhões alongados do queixo e olhos situados abaixo da borda lateral de uma cabeça larga e chata. Esses peixes atingem cerca de $60 \mathrm{~cm}$ e são comuns no comércio de peixes na Amazônia. Hypophthalmus é um peixe pelágico, nadador habilíssimo, que se locomove em grandes cardumes. A falta de uma mandíbula dentada e a presença de numerosas lamelas raspadoras, alongadas, sugerem uma dieta planctônica.

Uma espécie de Cetopsidae, Cetopsis coecutiens (Fig. 4f) foi examinada pela Fase IV. Com um corpo em forma de torpedo, e ranhuras para barbilhões e barbatanas peitorais, esses peixes são bem adaptados à vida em águas abertas rápidas. Numerosos espécimes foram capturados à noite com linha e anzol da popa do "Alpha Helix", enquanto este estava ancorado no rio Solimões, numa água corrente que atingia $8 \mathrm{~km} / \mathrm{h}$. Pouco se conhece da ecologia desses peixes, mas sua dieta provavelmente consiste primariamente de peixes pequenos e larvas de insetos aquáticos. Os peixes grandes e inermes também podem formar uma parte de sua dieta. Os maiores espécimes capturados tinham cerca de $23 \mathrm{~cm}$ de comprimento.

A respiração aérea está presente em muitos, se não em em todos, membros da Callichthyidae, inclusive a única espécie verificada pela Fase IV, Hoplosternum littorale (Fig. 4g). Esse peixe extremamente resistente é completamente revestido por fortes lâminas e atinge um tamanho de cerca de $20 \mathrm{~cm}$. Como é de esperar-se num peixe tão fortemente encouraçado, Hoplosternum é um peixe que vive no fundo; sua dieta provavelmente consiste primariamente de larvas de insetos aquáticos. Lowe-McConnell (1975) menciona que peixes do proximamente relacionada com o gênero Callichthys, também fortemente encouraçado, são capazes de locomover-se na terra por muitos metros e resistir a grandes flutuaçōes de temperatura. Hoplosternum foi observado pela Fase IV, locomovendo-se rapidamente e com facilidade sobre uma superfície seca e dura (neste caso, um convés de barco)

A última família de bagres pesquisada pela Fase IV foi a Loricariidae, os bagres de "boca sugadora" (Fig. 4f). Os membros dessa família são também bem adaptados à vida junto ao substrato, com pesada armadura, e, em muitos casos, uma forma de corpo rasa que é chata no abdômem e levemente convexa no dorso. Os loricarídeos têm bocas em forma de discos que podem ser usadas como dispositivo sugador, permitindo-lhes agarrarem-se à superfície de rochas, toros, ou raizes expostas e moverem-se lentamente raspando a matéria orgânica aderida. Esses peixes podem ser encontrados aderidos à madeiras em águas rápidas mas são igualmente habilitados a mover-se em fundos lodosos em lagoas estagnadas, onde comem lodo e dejetos. Essa adaptabilidade para tais habitats variados pode ser a razão de os loricarídeos abrangerem a maior família única dos bagres sul americanos, com cerca de 50-60 gêneros e acima de 400 espécies. Onze gêneros loricarídeos foram testados pela Fase IV. Atenção particular foi dada aos peixes dos gêneros Pterygoplichthys, Lo ricaria e Hypostomus dada a sua capacidade de respiração aérea suspeitada ou confirmada. A maioria dos loricarídeos năo ultrapassa de cerca de $30 \mathrm{~cm}$ de comprimento, mas alguns, por exemplo Pterygoplichthys, atingem quase $60 \mathrm{~cm}$. Pelo menos uma espécie de Loricarichthys exposta pela Fase IV não é descrita (Nijssen, litt.). Aqueles peixes relativamente grandes e características de uma das áreas mais intensamente amostradas da América do Sul, permanecem desconhecidos acentuando nossa falta de conhecimento dessa fauna.

A Ordem Atheriniformes (Superordem Atherinomorpha) é uma reuniăo diversa $e$ inclui os ciprinodontes, poecilídeos (por exemplo, o "guppy", Poecilia reticulata), "halfbea- 
ks" (Hemiramphidae), peixes agulha e o "peixe voador" marinho, e um número de outras formas menos familiares e nåo ictiólogos. O único membro desse grupo que foi amostrado pela Fase IV é o peixe agulha do gênero Potamorrhaphis (Belonidae), um peixe com mandibulas muito alongadas. Esse peixe é nadador ativo que nada logo abaixo da superfície da água, alimentando-se de insetos terrestres ou voadores que caem na água. Os espécimes de Potamorrhaphis capturados estavam em cardumes próximos ao meio de um pequeno córrego.

A superordem Acanthopterygii é o maior grupo mais recente em termos de origem filogenética. Os acantopteríginos ou peixes "raiados-espinhosos incluem um número enorme de famílias, gêneros e espécies, maioria dos quais não aparece no norte temperado. A maioria dos peixes "raiados-espinhosos" são marinhos e na água doce da América do Sul, esse grupo é muito obscurecido pelos estariofíseos. A maioria das espécies acantopteríginas que ocorrem na Amazônia não são "típicos" na aparência e são de importância periférica ao ecossistema. Os grupos de peixes remanescentes descritos abaixo pertencem a esse maior grupo.

Os Synbranchidae são muito atípicos dos Acanthopterygii. Alongados e como enguias na forma, os simbranquídeos atualmente são membros altamente especializados de sua própria ordem (Synbranchiformes) e de forma alguma aparentados com as enguias. Eles podem ser imediatamente identificados pela única câmara branquial abrindo-se na superfície ventral da cabeça. Duas espécies ocorrem na América do Sul, das quais somente uma, Synbranchus marmoratus (Fig. 4i) foi objeto de estudo amostrada pela Fase IV. S. marmoratus atinge um comprimento de cerca de $60 \mathrm{~cm}$ e comumente habita tocas numa grande variedade de habitats, incluindo lagoas, lagos e margens de rios. Quando a água circundante é pobremente aerificada, esses peixes respiram o ar da superfície pelo uso de uma câmara branquial especializada. Pouco se conhece da história natural do Synbranchus; normalmente ele é vağaroso e preda peixes e sapos (Breder, 1927; Zaret \& Rand, 1971). Synbranchus foi mencionado por Carter \& Beadle (1930) por estivar em tocas, muito parecido com a pirambóia, Lepidosiren.

De ordem Perciformes, a Fase IV examinou membros de duas famílias - Sciaenidae e Cichlidae. A Sciaenidae, ou corvinas, é a família de espécies predominantemente marinhas ou de estuário, mas algumas espécies ocorrem somente na água doce. Plagioscion é o único gênero scianídeo de água doce encontrado na Amazônia e ocorre bastante nas águas mais profundas, nos leitos do rio principal e nas formações periféricas. É um peixe de cardume que nada lentamente no fundo, alimentando-se de larvas de insetos e outra matéria orgânica. Embora as espécies desse gênero atinjam um comprimento acima de $60 \mathrm{~cm}$, a maioria dos espécimes examinados pela Fase IV tinha $45 \mathrm{~cm}$ ou menos. Plagioscion foram capturados no Paraná de Janauacá e no rio Negro.

Os acantopteríginos mais numerosos na América do Sul são os ciclídeos (Cichlidae, Fig. $4 \mathrm{j}$ ), um grupo de peixes caracterizados por um complexo aparelho faringeal da mandíbula (somente o Cichla, entre os gêneros sul americanos, não o tem). Esse aparelho permite aos ciclídeos tomarem bocados dos entulhos do fundo ou outras matérias misturadas separando alimentos desejados e expelindo matéria não comestível. Os ciclídeos são peixes evolutivamente avançados, com padrões de comportamento e histórias evolutivas muito complexos especialmente na Africa.

Onze gêneros de ciclídeos foram examinados pela Fase IV e, de muitas maneiras, eles são os mais interessantes dos peixes encontrados em termos de complexidade de hemoglobinas. A maioria dessas espécies é de peixes que "pairam", que nadam lentamente sobre o substrato e mordiscam quando o alimento é percebido. Por exemplo, membros do gênero Geophagus movem-se no fundo tomando bocados de areia, separando os alimentos e cuspindo fora a areia ou passando-se através das câmaras branquiais. Somente membros do gênero Cichla são predominantemente piscívoros, e a estratégia de captura de alimento é provavelmente ficar parado e aproximar-se vagarosamente da presa. Cichla é o maior ciclídeo na América do Sul e embora a sistemática do gênero esteja em desordem, espécimes considerados como sendo $C$. ocellaris foram 


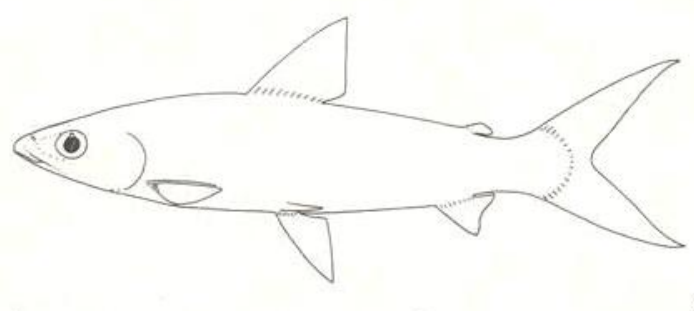

a

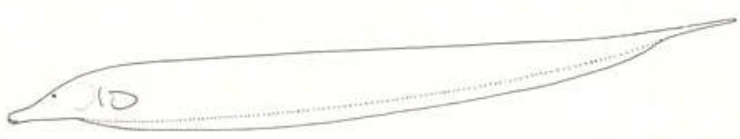

b

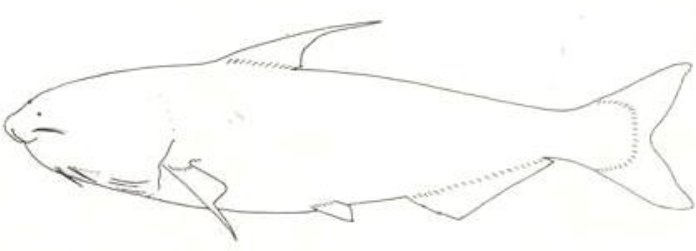

f
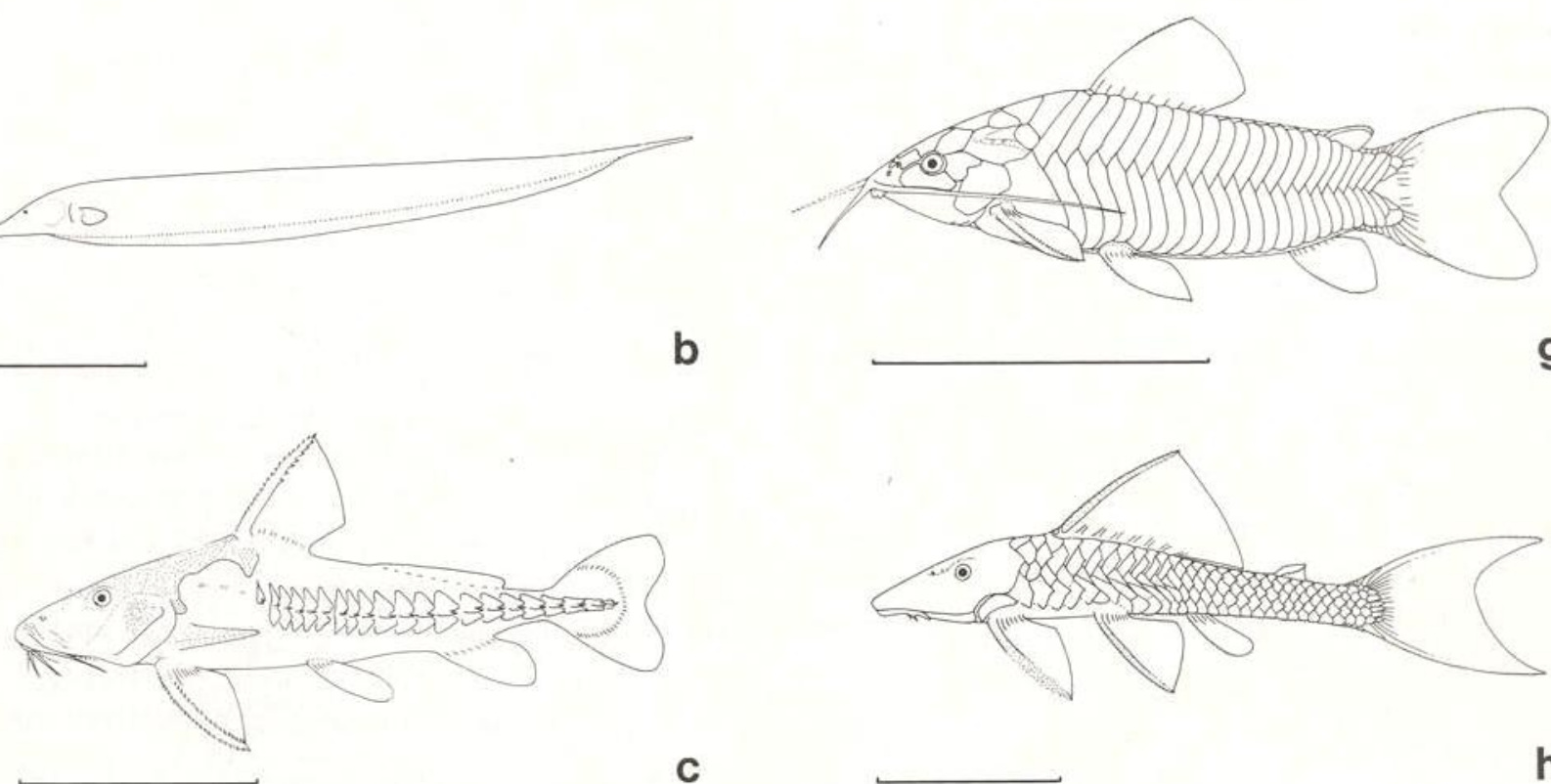

C

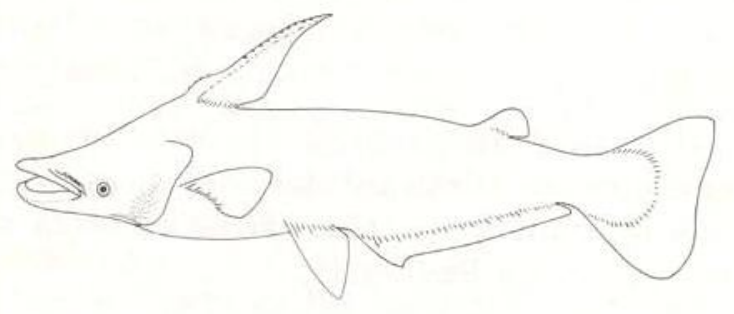

d
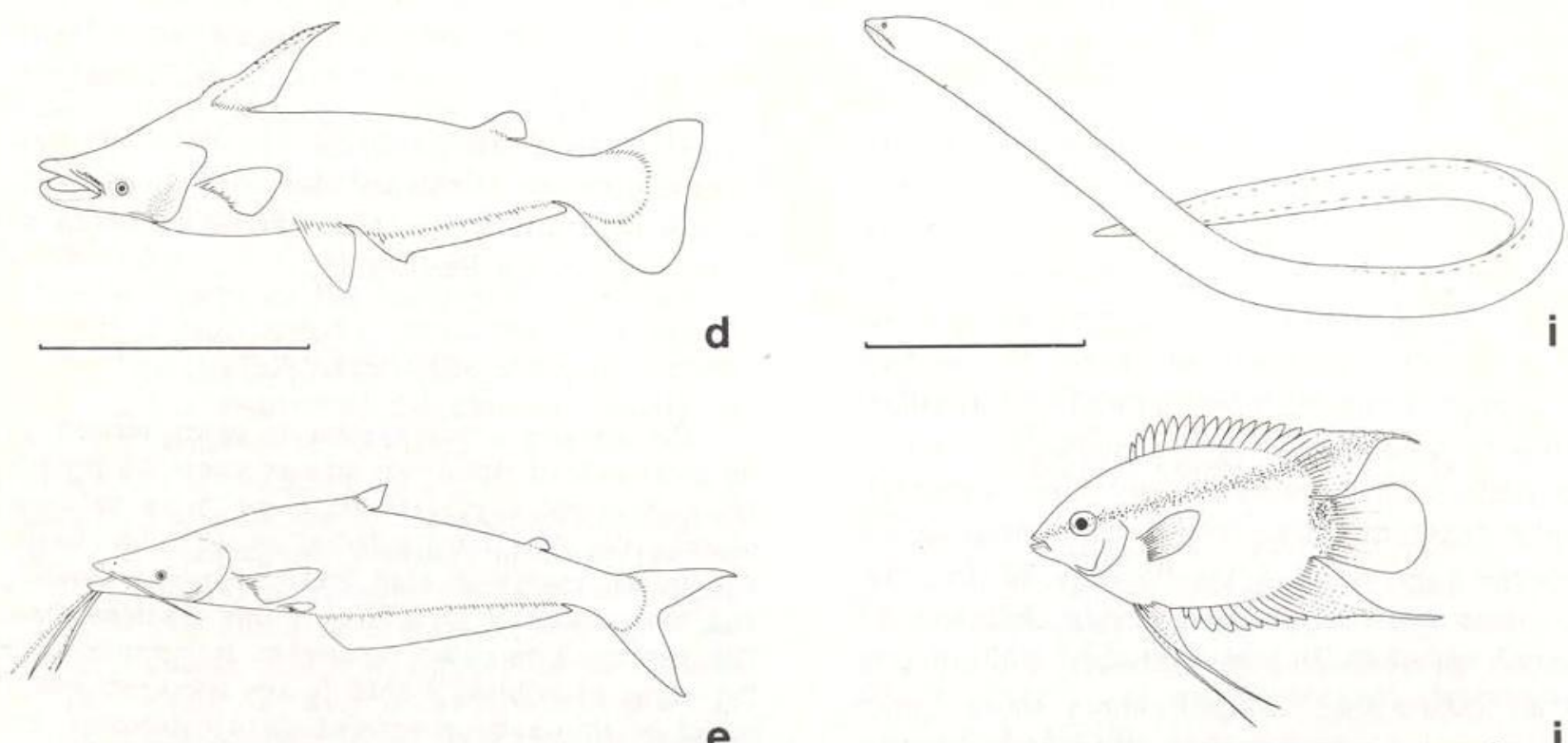

e

Fig. 4" Exemplos selecionados de peixes amazonenses: a) Hemiodus sp.; b) Rhamphichthys sp.; c) Pseudodoras niger; d) Ageniosus sp.; e) Hypophthalmus sp.; f) Cetopsis coecutiens; g) Hoplosternum littorale; h) Hypostomus sp.; i) Synbranchus marmoratus; j) Cichlasoma festivum. Linha $=10 \mathrm{~cm}$. 
mencionados por Lowe-McConnell (1960) por atingirem cerca de $50 \mathrm{~cm}$ de comprimento e cerca de $3,5 \mathrm{~kg}$ de peso. Machado (1971) registrou um espécime de $C$. ocellaris com 61,7 $\mathrm{cm}$ de comprimento padrảo (o peso não foi dado). A maioria das outras espécies examinadas pela Fase IV são consideravelmente menores, atingindo cerca de $14-20 \mathrm{~cm}$ de comprimento.

O único membro da Soleidae (ordem Pleuronectiformes) capturado durante a Fase IV foi Achirus, um pequeno peixe achatado com cerca de $20 \mathrm{~cm}$ de comprimento. Achirus é um habitante do fundo que jaz coberto por uma fina camada de limo do fundo e se alimenta de pequenos peixes ou invertebrados.

A ordem Tetraodontiformes está representada em toda a Amazônia por Colomesus psittacus (Tetraodontidae), um baiacu pequeno, com faixas amarelas e marrons com mais de $12 \mathrm{~cm}$ de comprimento. Esse peixe foi encontrado pela Fase IV ocorrendo em grande número nos campos ao longo da linha marginal do lago Janauacá. Como outros baiacus, ele é um peixe de movimentos relativamente lentos que aumenta grandemente o seu tamanho quando atacado ou molestado, enchendo seu abdômem com água. Apesar de um peixe comum, pouco se conhece de sua história natural; presumivelmente, contudo, ele se alimenta de larvas de insetos aquáticos.

No texto acima, nós tentamos fornecer ao leitor algum conhecimento da história natural, ecologia e sistemática, a fim de tornar os trabalhos seguintes deste artigo mais compreensíveis. A informação aqui apresentada é necessariamente esboçada, em parte por motivo de espaço limitado mas também, particularmente no caso da biologia e ecologia dos peixes, dada a carência de informações. Especialmente desalentadora foi nossa tentativa de fornecer aos participantes da Fase IV informações tais como história da vida, hábitos de natação, preferências de habitats e dieta dos peixes coletados. Simplificamos muito, mas tivemos pouca alternativa e podemos somente esperar que 0 interesse crescente pela fauna e flora dêssa área fascinante forneça o ímpeto à pesquisa, necessária para obter-se tal conhecimento.

\section{AGRADECIMENTOS}

O autor gostaria de expressar particularmente seus agradecimentos ao Dr. Austen Riggs, que ofereceu o convite para participar da Fase IV da cruzada do "Alpha Helix". Agradecimentos são também estendidos aos muitos membros da cruzada que pescaram, ficaram encharcados, sujos e mordidos por piranhas a fim de apanharem os numerosos espécimes examinados. Menção especial deve ser dada aos Drs. Hans e Unni Fyhn e B. Jeanne Davis por seus consideráveis esforços no campo. Aos Drs. Warwick E. Kerr e Wolfgang Junk que gentilmente proporcionaram a hospitalidade do INPA (Instituto Nacional de Pesquisas da Amazônia, Manaus) e providenciaram a remessa de peixes aos Estados Unidos, para identificação. Ao Sr. Robert Schoknecht, outrora do Museu de Zoologia Comparada e agora na Universidade Cornell, que auxiliou na identificação de espécimes e compilação da lista de espécies. Ao Dr. Han Nijssen e isaac Isbrucker que tiveram a bondade de fornecer identificações de vários bagres loricarídeos. Os fundos foram fornecidos pela subvenção do NSF, PCM $75-06451$ e pelo Museu de Zoologia Comparada, Universidade de Harvard.

Ambos os autores gostariam de agradecer aos Drs. S.H. Weitzman e D.L. Kramer pela leitura dos rascunhos do manuscrito e fornecimento de numerosos comentários úteis.

Os espécimes de prova das espécies examinadas pelos investigadores da Fase IV estão sendo devolvidos ao Museu de Zoologia da Universidade de São Paulo.

\section{SUMMARY}

The Amazon river system is characterized by its great size (it drains an area of about 6.5 million $\mathrm{km}^{2}$ ), its great depth (to $90 \mathrm{~m}$ or more in some places), the flat topography of its drainage basin, the annual cycles of high and low water periods, and the geological structure of the drainage area. The central Amazonian ecosystem is complex and the types of habitat within it are numerous, with broad overlap and intergradation of categories. An especially important factor in the aquatic habitat is water type ("white", "black" or "clear"), a characteristic which is related to the geological character and the flora of the drainage area. Cyclical changes in water level and associated 
fluctuations in the availability of oxygen are two factors which exert considerable influence over the biology of central Amazonian fishes. The collection sites of Alpha Helix Phase IV are described briefly. The systematics and evolution of most Amazonian fish groups are poorly known; the inability to identify all fishes examined and lack of well-tested evolutionary hypotheses of relationship on which to base comparisons pose problems for the comparative biologist. A brief survey of general aspects of phylogeny and of the natural history of fishes examined by Phase IV is presented, including, when possible, information about habitat preferences, food and other aspects of the biology of the fishes.

\section{BIBLIOGRAFIA}

BENNETT, M.F.L.

1970 - Comparative physiology: electric organs. Annual Review of Physiology, 32:470-528.

1971a - Electric ogans. In: Fish Physiology, (eds. HOAR, W. S. \& RANDALL, D. J.) New York, Academic Press. v. 5.347-491.

1971b - Electroreception, ibid. : 493-574.

BöhlKe, J.E.; WeITZMAN, S.H. \& MENezes, N.A.

- The status of South American freshwater systematic ichthyology. Acta Amazonica (in press.)

Bonetto, A.E.; Cordiviola, C.; Pignalberi, C. \& OLIVEIRA, O.

1969 - Ciclos hidrologicos des rio Paraná y las poblaciones de peces contebidas en las cuencas temporaais de su valle de inundacion. Physis (Buenos Aires), 29 (78) : 215-223.

BREDER JR., C.M.

1927 - The fishes of the rio Chuncunaque drainage, Eastern Panamá. Bulletin of the American Museum of Natural History, $57: 91-176$.

CARTER, G.S.

1934 - Results of the Cambridge Expedition to British Guiana, 1933. The fresh waters of the rain-forest areas of British Guiana. The Journal of the Linnean Society of London, 34 : 147-193.

Carter, G.S. \& Beadle, C.

1930 - Notes on the habits and development of Lepidosiren. Journal of the Linnean Society of London (Zoology) $37: 197-203$.

1931 - The fauna of the swamps of the Paraguayan Chaco in relation to its environment. II. Respiratory aclaptations in the fishes. Journal of the Linnean Society of London (Zoology), $37: 327-368$.

DUCKE, A. \& BLACK, G.A.

1953 - Phytogeographical notes on the Brazilian Amazon. Anais da Academia Brasileira de Ciências, 25(1):
ELLIS, M.M.

1913 - The gymnotid eels of troptcal America. Memoirs of the Carnegie Museum, 6(3): 109-204.

FrrtkaU, F.J.

1967 - On the ecology of Amazonian rain-forest streams. Atas do Simpósio sobre a Bio. ta Amazônica (Limnologia) $3: 97-108$.

FYhN, U.E.H.; FYhN, B.J.; DAvis, B.J.; POWers, D.A.; Fink, W.L. \& GaRilick, R.L.

1978 - Heterogeneidade de hemoglobinas nos peixes da Amazônia. Acta Amazonica 8(4): Suplemento. (Este volume).

GreenWood, P.H.; Rosen, D.E.; WeItzman, S.H.

\& MYERS, G.S.

1966 - Phyletic studies of teleostean fishes, with a provisional classification of living forms. Bulletin of the American Museum of Natural History, $131: 339-456$.

GUDGer, E.W.

1943 - The giant fresh-water fishes of South America. The Scientific Monthly, 57: 500-513.

HAFFER, J

1974 - Avian speciation in tropical South America. Publications of the Nuttall Ornithological Club. (14) Cambridge, Mass.

HaLstead, B.W.

1970 - Poisonous and venomous marine animals of the world. Washington, D.C., Government Printing Office. vol. 3

HochachKa, P.W. \& SOMERo, G.N.

1971 - Biochemical adaptation to the environment. In: Fish Physiology, New York, Academic Press, v. 6 pp 99-156.

Hopxins, C.D

1974 - Electric communication in the reproductive behavior of Sternopygus macrurus (Gymnotoidei). Zeitschrift für Tierpsychologie, $35: 518-535$.

JENKINS, R.E.

1976 - A list of undescribed freshwater fish species of continental United States and Canada, with additions to the 1970 checklist. Copeia, v(3): 642-644.

JUNK, W.

1970 - Investigations on the ecology and production biology of the "floating meadows" (Paspalo-Echinochloetum) on the Middle Amazon. Part I: The floating vegetation and its ecology. Amazoniana, 2 : $449-495$.

KNÖPPEL, H.A.

1970 - Food of central Amazonian fishes. Contribution to the nutrient-ecology of Amazonian rain-forest streams. Amazoniana, 2(3) : 257-352. 
Kramer, D.L.; Lindeey, C.C.; Moodie, G.E. \& STEVEns, E.D.

s/d - Respiratory ecology of the fishes of the central Amazon basin. Canadian Journal of Zoology (In press).

LOWE-MCCONNELL, R.H.

1969 - The cichlid fishes of Guyana, South America, with notes on their ecology and breeding behavior. Zoological Journal of the Linnean Society, $44: 255-302$.

1975 - Fish communities in tropical freshwaters. New York, Longman Inc.

MACHADO-ALlison, A.

1971 - Contribucion al conocimiento de la taxonomia des genero Cichla (Perciformes: Cichlidae) en Venezuela. Parte I. Acta Biol. Venez., 7(4) : 459-497.

Mago-Leccis, F.

1972 - Consideraciones sobre la sistematica de la familia Prochilodontidae con una sinopsis de las especies de Venezuela. Acta. Biol. Venez., $8: 35-96$.

MARLIER, G.

1967 - Ecological studies on some lakes of the Amazon valley. Amazoniana, 1(2):91-115.

1968 - Les poissons du lac Redondo et leur régime alimentaire: les chaînes trophiques du Lac Redondo; les poissons du Rio Prêto de Eva. Cadernos da Amazônia, $2: 21-57$.

1973 - Limnology of the Congo and Amazon Rivers. In: Tropical Forest Ecossystems in Africa and South America: a comparative review. (ed. B. J. Meggars, et al.) Washington, D.C., Smithsonian Institution Press. p. 223-238.

MEgGers, B.J.

1971 - Amazonia. Man and Culture in a Counterfeit Paradise. Chicago, Aldine Publishing Co.

MIGDALSKI, E.C.

1957 - Contribution to the life history of the South American fish Arapaima gigas. Copeia, (1) : 54-56.

MYERS, G.S., ed.

1972 - The Piranha book. New Jersey, T.F.H. Publications.

Powers, D.A.; Fyhn, H.J. Fyhn, U.E.H.; Martin, J.P.; GARLICK, R.L. \& WOOD, S.C.

1978 - Estudo comparativo de equilíbrio de oxigênio no sangue de 40 gêneros de peixes da Amazônia. Acta Amazonica 8(4): Suplemento. (Este volume).

ROBERTS, T.R.

1969 - Osteology and relationships of characoid fishes, particularly the genera Hepsetus, -Salminus, Hoplias, Ctenolucius, and Acestrorhynchus. Proceedings of the California Academy of Sciences, 36(15): 391-500.
1972 - Ecology of fishes in the Amazon and Congo basins. Bulletin of the Museum of Comparative Zoology. 143(2):117-147.

SAUL, W.G.

1975 - An ecological study of fishes at a site in upper Amazonian Ecuador. Proceedings of the Academy of Natural Sciences of Philadelphia, 127(12) : 93-134.

SCHMIDT, G.W.

1973 - Primary production of phytoplankton in the three types of Amazonian waters. II. The limnology of a tropical floodplain lake in central Amazonia (Lago de Castanho). Amazoniana, 4(2): 139-203.

SCHULTZ, L.P.

1950 - Review of thirteen genera of South American fishes in the subfamilies Cynodontinae, Hepsetinae, and Characinae with a description of a new Cyrtocharax. Studies honoring Trevor Kincaid. Seattle, University of Washington, p. 43-73.

SchwassmanN, H.O.

1976 - Ecology and taxonomic status of different geographic populations of Gymnorhamphichthys hypostomus Ellis (Pisces, Cypriniformes, Gymnotoidei). Biotropica, 8(1) : 2540 .

Sioli, $\mathrm{H}$.

1957 - Valores de pH de Aguas Amazônicas. Boletim do Museu Paraense Emilio Goeldi (Geologia), 1: 1-37.

1964 - XI. Amazoniana. General feactures of the limnology of Amazonia. Internacionale Vereinigung für Theoretische und Angewandte Limnology, 15:1053-1058.

1967 - Studies in Amazonian waters. Atas do Simpósio sobre a Biota Amazônica. (Limnologia) $3: 9-50$.

1968 - Hydrochemistry and geology in the Brazilian Amazon Region. Amazoniana 1(3) : 267-277.

STARK, N.

1970 - The nutrient content of plants and soils from Brazil and Surinam. Biotropica, 2(1) : $51 \cdot 60$.

Steinbach, A.B.

1970 - Diurnal movements and discharge characteristics of electric gymnotid fishes in the Rio Negro, Brazil. The Biological Bulletin, 138(2): 200-210.

WeITZMAN, S.H.

1962 - The osteology of Brycon meeki, a generalized characid fish, with an osteological definition of the family. Stanford Ichthyological Bulletin, 8(1): 3-77.

ZARET, T.M. \& RAND, A.S.

1971 - Competition in tropical stream fishes. Ecology, 52(2) : 336-342. 